Florida International University FIU Digital Commons

7-2-2014

\title{
Does the Pareto Distribution of Hurricane Damage Inherit its Fat Tail from a Zipf Distribution of Assets at Hazard?
}

Javiera I. Hernandez

Florida International University, jhern385@fiu.edu

DOI: $10.25148 /$ etd.FI14071154

Follow this and additional works at: https://digitalcommons.fiu.edu/etd

\section{Recommended Citation}

Hernandez, Javiera I., "Does the Pareto Distribution of Hurricane Damage Inherit its Fat Tail from a Zipf Distribution of Assets at Hazard?" (2014). FIU Electronic Theses and Dissertations. 1488.

https://digitalcommons.fiu.edu/etd/1488 


\title{
FLORIDA INTERNATIONAL UNIVERSITY
}

Miami, Florida

\section{DOES THE PARETO DISTRIBUTION OF HURRICANE DAMAGE INHERIT ITS FAT}

TAIL FROM A ZIPF DISTRIBUTION OF ASSETS AT HAZARD?

\author{
A thesis submitted in partial fulfillment of \\ the requirements for the degree of \\ MASTER OF SCIENCE \\ in \\ GEOSCIENCES \\ by \\ Javiera I. Hernandez
}


To: Interim Dean Michael R. Heithaus

College of Arts and Sciences

This thesis, written by Javiera I. Hernandez, and entitled Does the Pareto Distribution of Hurricane Damage Inherit its Fat Tail from a Zipf Distribution of Assets at Hazard?, having been approved in respect to style and intellectual content, is referred to you for judgment.

We have read this thesis and recommend that it be approved.

Robert Burgman

Haiyan Jiang

Hugh E. Willoughby, Major Professor

Date of Defense: July 2,2014

The thesis of Javiera I. Hernandez is approved.

Interim Dean Michael R. Heithaus

College of Arts and Sciences

Dean Lakshmi N. Reddi

University Graduate School

Florida International University, 2014 


\section{ACKNOWLEDGMENTS}

First and foremost, I'd like to thank my Major Advisor, Professor Hugh E. Willoughby. Without his vision, leadership, and knowledge this thesis would not have been made a reality. I'd also like to acknowledge the Department of Earth and Environment graduate

director, Dr. Laurel Collins for her aide in the possibility for FIU funding through a teaching assistantship. My committee members Drs. Robert Burgman and Haiyan Jiang have also been essential in the process of this thesis. Finally, I'd like to thank my family for their ongoing love and support. 
ABSTRACT OF THE THESIS

DOES THE PARETO DISTRIBUTION OF HURRICANE DAMAGE INHERIT ITS

FAT TAIL FROM A ZIPF DISTRIBUTIONS OF ASSETS AT HAZARD?

by

Javiera I. Hernandez

Florida International University, 2014

Miami, Florida

Professor Hugh E. Willoughby, Major Professor

Tropical Cyclones are a continuing threat to life and property. Willoughby (2012)

found that a Pareto (power-law) cumulative distribution fitted to the most damaging 10\% of US hurricane seasons fit their impacts well. Here, we find that damage follows a Pareto distribution because the assets at hazard follow a Zipf distribution, which can be thought of as a Pareto distribution with exponent 1 . The Z-CAT model is an idealized hurricane catastrophe model that represents a coastline where populated places with Zipfdistributed assets are randomly scattered and damaged by virtual hurricanes with sizes and intensities generated through a Monte-Carlo process. Results produce realistic Pareto exponents. The ability of the Z-CAT model to simulate different climate scenarios allowed testing of sensitivities to Maximum Potential Intensity, landfall rates and building structure vulnerability. The Z-CAT model results demonstrate that a statistical significant difference in damage is found when only changes in the parameters create a doubling of damage. 


\section{TABLE OF CONTENTS}

CHAPTER

PAGE

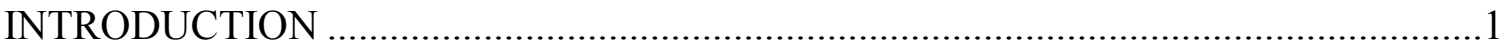

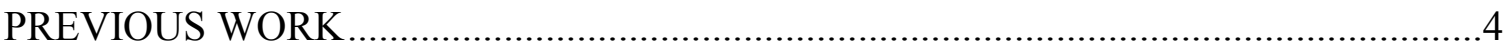

Tropical Cyclone Dynamics ...............................................................................4

Normalized Damage from Landfalling US Hurricanes ...................................5

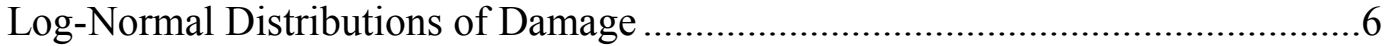

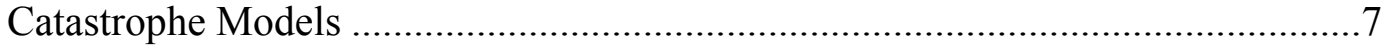

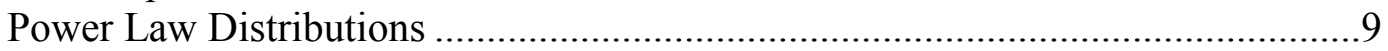

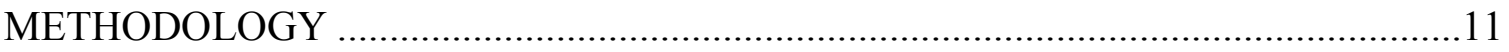

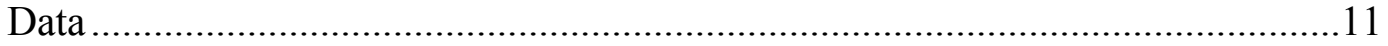

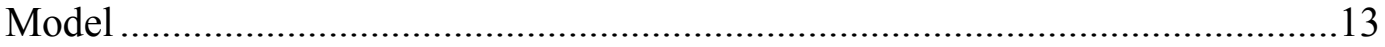

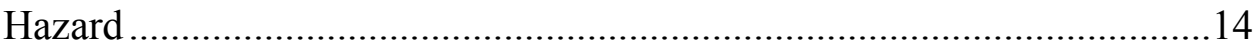

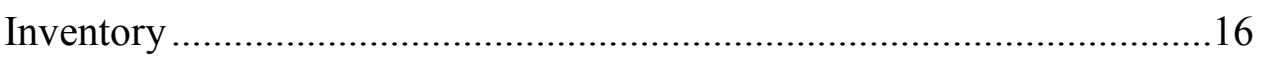

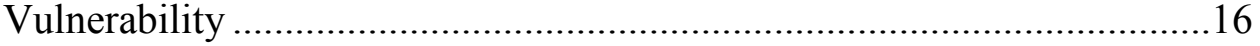

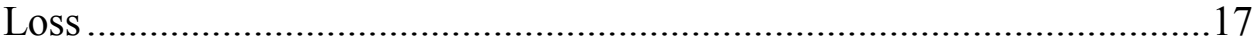

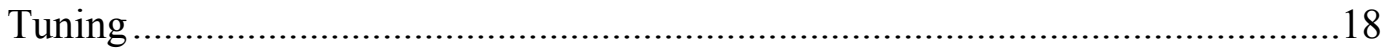

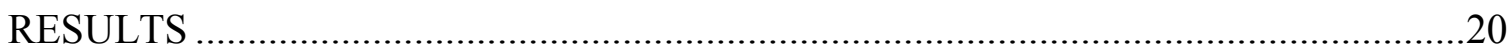

Z-CAT Simulating 113 Hurricane Seasons .....................................................20

Z-CAT Simulating Changes in Climate and Building Standards .......................28

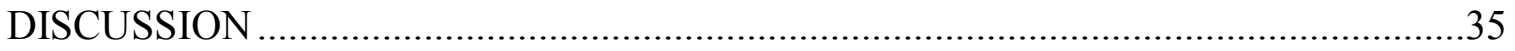

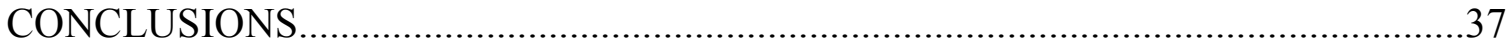

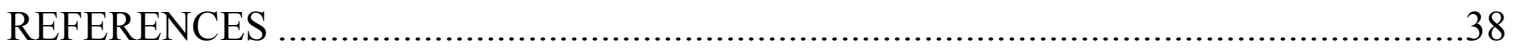




\section{LIST OF FIGURES}

FIGURE

PAGE

1. Pareto distribution of hurricane damage ............................................................. 11

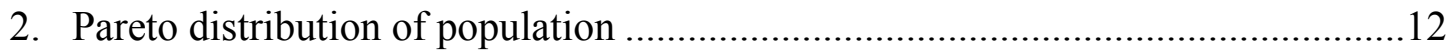

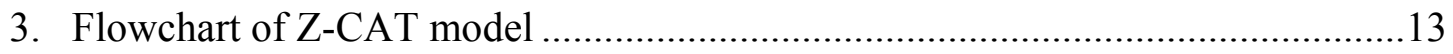

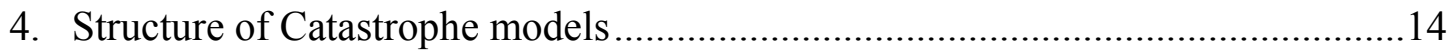

5. Wood-White parameterized hurricane wind profile ........................................ 15

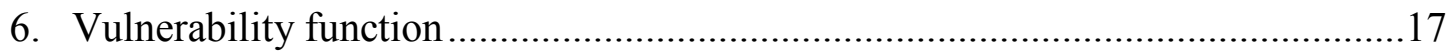

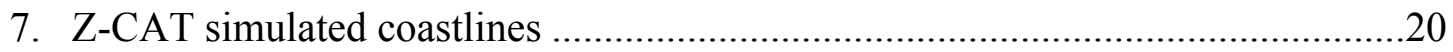

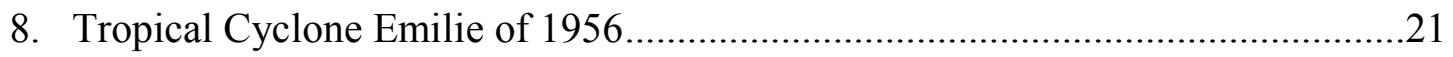

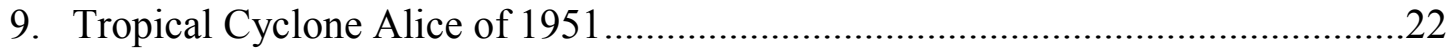

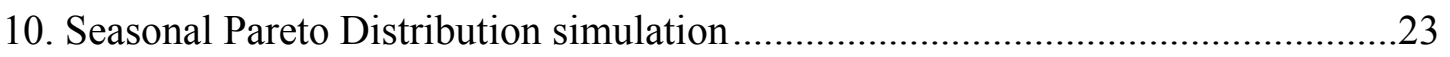

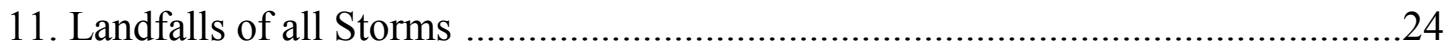

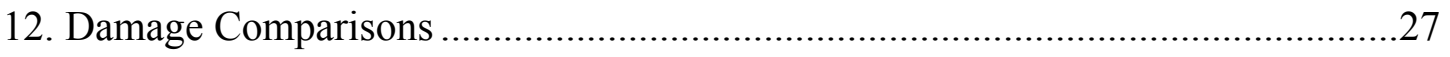

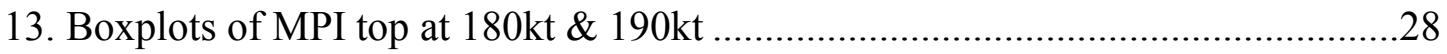

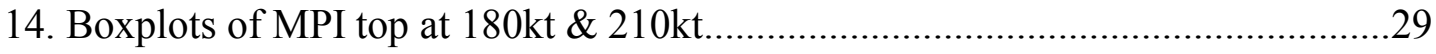

15. Bar Graphs of Statistical Tests for MPI top comparisons....................................30

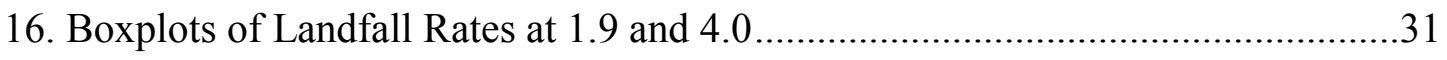

17. Bar Graphs of Statistical Tests for Landfall comparisons ..................................32

18. Boxplots of top of Vulnerability Curve at 180kt \& 210kt ................................33

19. Bar Graphs of Statistical Tests for bottom of Vulnerability Curve ......................33

20. Bar Graphs of Statistical Tests for top of Vulnerability Curve ............................34 


\section{ABBREVIATIONS, ACRONYMS AND SYMBOLS}
AMO
Atlantic Multidecadal Oscillation
$\alpha$
Alpha Pareto Exponent
CAT
Catastrophe
Coast_Length
Length of simulated coastline
D
Damage
$d$
damage
$D_{o}$
Cumulative Damage
ENSO
El Niño Southern Oscillation
FRIC_FRAC
Surface Roughness
Kts
Knots
LL
Lambda, width of wind maxima
MPI
Maximum Potential Intensity
MPI_BOT0
Lower bound threshold for MPI
MPI_TOP0
Upper bound threshold for MPI
$N$
Populated Places
$n$
Rank 


$$
\text { Nin }
$$

Nout

Po

pop_places

RATE 0

RATE_R

$\mathrm{Rmax}$

RUN_ID

StartYear

Seasons

$S_{n}$

$\mathrm{TC}$

threshold_sea

threshold_strm

Vmax

US

Zipf_max
Slope of wind from Rmax to Vmax

Slope of wind from Vmax outward

Probability

Number of population centers

Hurricane landfall rate

Rate of change over time for landfall rate

Radius of Maximum Wind

Set up file Identification

Year that begins simulation

Number of seasons simulated in Z-CAT

Size

Tropical Cyclone

Percent of seasons on the tail of the distribution

Percent of storms on the tail of the distribution

Maximum Wind

United States

Value of most populated center 


\section{INTRODUCTION}

In summer and fall, tropical cyclones threaten the vulnerable, densely populated United States (US) coast. Historical damage scaled for population, inflation and individual wealth (Pielke et al. 2008) shows zero trends. Pielke et al. attempted two normalization schemes to scale past US Tropical Cyclone (TC) damage to 2005 coastal development. The original normalization was based on inflation, wealth and population, but may have underestimated contemporary losses. Nonetheless, the second scheme, that considers inflation, wealth, and number of households, yielded consistent results.

While historical records of damage do not show a 1900-2005 trend, random, rare events cause extreme damage. Those "Black Swans" (Taleb 2007) lie on the "fat tail" of the statistical distribution. For example, in 2005 Hurricane Katrina devastated the Gulf Coast and destroyed \$108 billion dollars in property (Knabb 2005). In 2012 "Superstorm Sandy" struck the Northeast coast causing an estimated $\$ 50$ billion dollars in damage (Blake et al. 2013). Hurricane intensity is limited thermodynamically by the oceanic energy source, and size is limited dynamically by the requirement that the ratio of winds' rotation about the cyclone center to the rotation of the Earth (the "Rossby number") be much greater than one. Given the physical limitations on the hazard, the fat tail of the damage distribution must stem from the distribution of assets at risk.

The windstorm insurance industry uses catastrophe ("CAT") models to estimate the statistical distribution of losses to be expected for a given insurer's "book of business". Catastrophe models consist of four modules: hazard, inventory, vulnerability and loss. The hazard module describes location, frequency and severity of the damaging 
geophysical events, which is generally developed using historical data. The inventory module is a database of the property characteristics, values, and locations. The vulnerability module uses functions based upon experience or rational analysis to link the hazard intensity to structural damage, and the loss module translates physical damage to financial losses or claims payouts (Grossi and Kunreuther 2005).

Hurricane damage can be described using power law distributions that approximate rare, extreme events on the tails of more general distributions. One example is the Pareto distribution where the cumulative statistical distribution of some quantity, $D$, varies inversely as a power $\alpha$ of that quantity. It is named after the economist Vilfredo Pareto who used it to describe the wealth of people in Italy. He found that most of the wealth was in the hands of a few people while most lived in poverty. A special case of power law, is the Zipf distribution, which is used by geographers to describe populated places when ranked by their sizes, such that the sizes of the places are inversely proportional to their ranks. Therefore, the second largest populated place is $1 / 2$ the size of the most populated place, the third is $1 / 3$ of the size of the first, and so on. Since the exponent in the Zipf distribution is equal to one, it is a special case of the Pareto distribution with $\alpha=1$. Willoughby (2012a) fitted a Pareto distribution to seasonally aggregated damage from the most damaging $10 \%$ of US hurricane seasons in an effort to answer the question: "Is a trillion dollar hurricane possible?"

Here, we create an idealized catastrophe model, Z-CAT, that illustrates the relation between assets at hazard and damage. The Z-CAT model considers clusters of vulnerable property that obey a Zipf distribution. These "populated places" are scattered 
randomly along a linear coastline. The virtual country, "Zipfistan", is then damaged by randomly generated hurricanes whose frequencies, sizes, and intensities are scaled to resemble those affecting the US Atlantic and Gulf of Mexico coasts. The intent is to produce multiple realizations of hurricanes in Zipfistan drawn from the same statistical distribution and to simulate their property casualties over several simulated centuries. With these results, it is possible to understand the relation between the distributions of assets and damage. Evaluating a climate signal by changing the frequencies or intensities of the hurricanes is reasonably easy with Z-CAT. One can argue that, because of the dominance of a few spectacularly destructive events, statistically significant increases in hurricane property casualties are a lagging indicator of the threat. The present study tests the hypothesis that Pareto distributions of hurricane damage inherit their tails from Zipf distributions of assets with the idealized Z-CAT hurricane catastrophe model. It also explores the power of Z-CAT to look into the ways that changes in climate affect the Pareto damage curve. 


\section{PREVIOUS WORK}

Tropical Cyclone Dynamics

Tropical Cyclones (TCs) are physically limited in both intensity and size. The limit on TC's intensity is their thermodynamically possible Maximum Potential Intensity (MPI). The MPI is estimated by assuming that tropical cyclones act like classical Carnot heat engines (Emanuel 1986). Energy is extracted as latent and sensible heat from the sea by air flowing inward in the high-wind boundary layer of the TC core. The air ascends to the upper troposphere in the TC eyewall, converting latent heat to sensible heat.

Ultimately the air flows outward to the TC environment carrying waste heat with it. The difference between the heat extracted and heat exhausted is available to do work against friction and defines the TC's thermodynamic efficiency. The heat acquired from the moist enthalpy of the sea surface and lost to the surroundings are proportional to the $\sim 100 \mathrm{~K}$ difference between the sea-surface and outflow absolute temperatures (Emanuel 1986, 1999). Generally a cyclone can never intensify to become stronger than its MPI calculated from the ocean and outflow temperatures. Because of environmental shear (Marks et al. 1992, Frank and Ritchie 2001), storm induced cooling of the sea (Mainelli et al. 2008) and eyewall replacements (Willoughby 1990, Sitkowski et al. 2011), most TCs fail to reach their MPI. Observed Hurricane intensities appear to be uniformly distributed between the threshold of hurricane intensity and their local MPI (Emanuel 2000). The Rossby number constrains size because it must be somewhat greater than unity (Shapiro \& Willoughby 1982) for air-sea interaction theory of MPI to work. If TCs are physically limited, why is there such a large variance in the historical damage? 
Normalized Damage of Landfalling US Hurricanes

While the climatology of hurricane landfall frequency is well documented in the HURDAT climatology (e.g., Landsea et al. 2004), a different perspective for insurers is looking at the way damage has been distributed through history. Pielke et al. (2008) used two normalization schemes and looked at damage due to U.S. Gulf and Atlantic landfalling TCs from 1900 to 2005. The first normalization methodology adjusts historical data for inflation, wealth and population updated to 2005. The second methodology (Collins and Lowe 2001) adjusts for inflation, wealth, and housing units, also updated to 2005 .

In the first normalization, inflation is adjusted for the years 1929 to 2005 by using the implicit price deflator for Gross Domestic Product data and for before 1929 using the data from Johnston and Williamson (2006). The ratio of the 2005 data to that of the year of the event occurrence is the adjuster. The adjustment for growth in wealth done second, increasing wealth simply means a growth in absolute terms of personal property that people own. The ratio of wealth is corrected for inflation and then applied to the normalized value. Finally the population adjustment is calculated on the basis of the growth of the counties affected by the cyclone. It is important to note that when adjusting for population, the authors use county-level census data which are available only at decadal intervals. The intervening years are interpolated linearly. The resulting multiplier, the ratio of damage in 2005 to damage that occurred in the year of the event, is applied to the data. 
Damage scaled for inflation alone shows an increasing trend. Scaling for inflation, wealth and either population or households achieved essentially the same results, zero trend. This zero trend outcome demonstrates that the long term increase trend in inflation-adjusted damage stems from economic and demographic changes. What is apparent, however, is that rare and extreme events, such as the 1900 Galveston Hurricane, the 1926 Miami Hurricane and Katrina of 2005, dominate the record.

\section{Log-Normal Distributions of Damage}

Willoughby (2012b) analyzed annually aggregated US hurricane damage and mortality. By using an annual aggregate instead of individual landfalls one can measure economic and climatic century-scale changes. Willoughby's (2012b) study, focused on 1900-2008, derives statistical trends and probability density functions for hurricane impacts. The data demonstrate an inverse variation between death rate and damage. Despite increasing population of vulnerable coastal areas, annually averaged deaths decrease from 478 in 1900 to 26 in 2008 because of the improvements in track forecasting. The halving time of mortality is 25.8 years. On the other hand, inflationadjusted damage shows an increase from $\$ 12$ million dollars in 1962 to $\$ 121,000$ million in 2005. Damage grew exponentially with a doubling time of 13.7 years from 1900-2008. As discussed previously, damage normalized for inflation, population, and wealth (Pielke et al. 2008), shows zero trend. Large random variations between seasons and increasing growth of property at risk are better analyzed with logarithmic transformations. The study found that the mean annual number of deaths and damage in the early $21^{\text {st }}$ century were 28 and $\$ 11$ billion. There is no trend attributable to anthropogenic global warming which 
is consistent with a consensus that global warming threatens to increase in intensity and frequency of the strongest hurricanes, but that a significant signal will probably remain undetectable before the late $21^{\text {st }}$ century (Bender et al. 2010, Knutson et al. 2010).

\section{Catastrophe Models}

Insurance and reinsurance companies use catastrophe (CAT) models to determine what rates to charge their policy holders. The CAT models, or loss models as they are termed by Watson and Johnson (2004), employ five components: input database, wind model, boundary layer, a vulnerability function and a frequency model. Watson and Johnson assessed nine wind models, four surface friction models and nine damage models in 324 combinations to compare model results with actual reported hurricane losses. The models use a minimum of three input databases: land cover, historical storm tracks, and exposure. Wind models could be either simple Rankine Vortices or more complicated parametric models which took into consideration specific hurricane characteristics. The boundary layer model calculated the reduction of the damaging winds (10 m elevation, 1 min averaging time) because of surface friction as a multiplicative correction. Vulnerability functions related wind speed to the percent damage. Lastly, the frequency function was determined either by counting historical events and fitting probabilities to coastal segments or by reproducing hurricanes with Monte-Carlo track and intensity models. Comparisons among models found that loss costs, even for the four best combinations diverged widely, especially for inland areas. Variation among the models was primarily attributable to choice of damage function, because of damage 
functions' nonlinearity. Watson and Johnson (2004) concluded that much more research had to be done to improve accuracy of loss models.

Katz (2002) used stochastic approach to catastrophe modeling based upon Pielke et al. (1998) normalized damage. His compound Poisson process used two components, to represent on the occurrence of events and the damage caused by each event. Damage totals were therefore "random sums" in which the variation of damage could be attributed to both the frequency of events and the damage from individual hurricanes. Katz found that no trend over time for event occurrence exists and that any apparent increase may result from lack of records in early part of the record. Damage caused by individual events are well fitted with lognormal distributions. Therefore, given the work done by Willoughby (2012b) and Katz (2002), we conclude that log-normal distributions or combinations of lognormal distribution are suitable for descriptions of seasonally aggregated and individual hurricane loss.

The HAZUS-MH hurricane model also uses the modular formulation. It is based on wind engineering models and estimates damage that results from rainfall that may enter buildings through broken windows and doors (Vickery 2006). The HAZUS-MH model was the first of its kind to use a national database of ground roughness. The model was validated through comparisons to observed damage.

A separate study by Grossi and Kunreuther (2005) points out that probabilistic approaches are best suited for natural hazard phenomena mostly because big catastrophes occur at such low frequencies. Because representation of these phenomena requires complex inputs, their view of catastrophe models has four modules: hazard, inventory, 
vulnerability, and loss. The hazard module represents location event, frequency, and severity generally derived from historical data. The inventory module is a database of the property characteristic, values, and location. The vulnerability module applies damage functions that link the intensity of damaging weather elements to their effect on structures, and finally a loss module translates the physical damage to total repair or replacement costs and ultimately to claims.

\section{Power Law Distributions}

A Zipf distribution is a power law distribution, sometimes called "Zipf's law" that describes sizes of population centers well. In the Zipf distribution, $N$ "populated places" are ranked by size $S$, from the largest $n=1$ to the smallest $n=N$, such that:

$$
S_{n}=\frac{S_{1}}{n}
$$

On a log-log plot of rank versus size, Zipf distributions appear as straight lines with slope equal to -1 . The slope of the line means that the probability that a populated places is greater than or equal to some $S$ is proportional to the reciprocal of $S$ (Gabiax 1999). In the United States Los Angeles is half as large as New York and Chicago is one third as large as New York. However once $n$ becomes large, the difference in size between $S_{n}$ and $S_{n+1}$ is small.

The Pareto distribution is a more general power law function. The Pareto distribution:

$$
\operatorname{Pr}\{d \geq D\}=P_{o}\left(\frac{D_{0}}{D}\right)^{\alpha},
$$


defines the cumulative probability that damage, $d$, is greater than $D$. It applies only to a more general distribution's tail, defined by cumulative damage $\geq D_{o}$, which has probability $P_{o}$. The exponent $\alpha$ defines shape of the tail beyond $D_{o}$. To a great extent, the Zipf distribution is a Pareto distribution with $\alpha=1$. The key difference between the Pareto distribution and the Zipf distribution is that the latter describes all of the populated places; whereas the former describes only the tail of the distribution with $\mathrm{d}>D_{\mathrm{o}}$. Power laws thus can describe rare, extreme events on the tails of more general distributions. 


\section{METHODOLOGY}

Data

Willoughby (2012b) found that approximately $2 / 3$ of US damage has occurred during the most damaging $10 \%$ of hurricane seasons. When seasonally aggregated or individual hurricane damage are fitted with Pareto distributions, Pareto exponents were $\alpha=1.37$ and 1.14 , respectively. As expected, the exponents of this data are close to one, the value that would describe a Zipf distribution. The key hypothesis here is that the Pareto exponents of aggregated and indvidual damage inherit these fat tails because assets at risk obey Zipf's law.

To explore this hypothesis, Census data from the 436 US coastal counties was tested to see if their populations follow Zipf's law. Data for each decadal census from
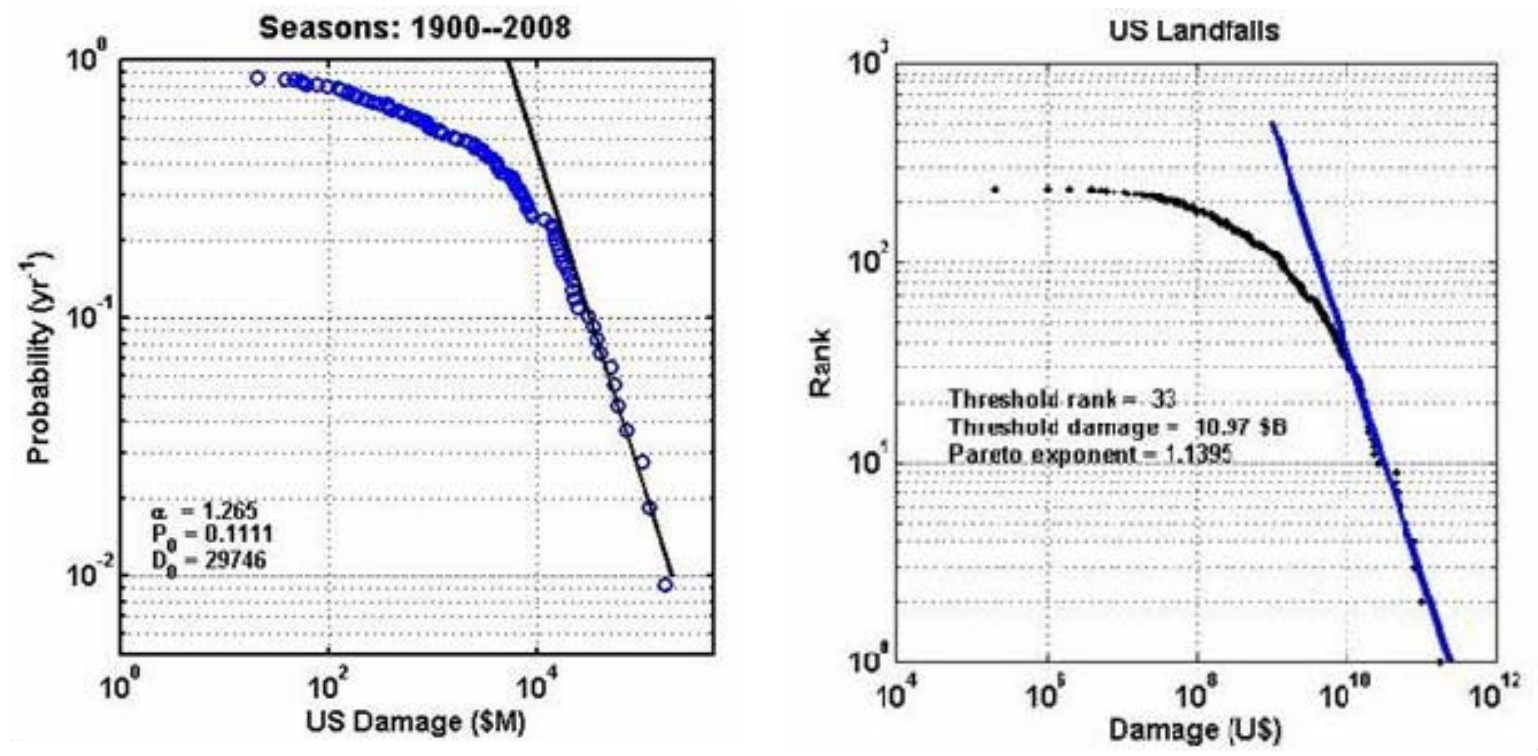

Figure 1. Pareto distributions of 1900- 2008 hurricane damage for seasons and individual landfalls. The alpha exponents are 1.37 and 1.14 respectively. 
1900 through 2010 were ranked from largest to smallest, plotted on a log-log graph, and fitted with Pareto distributions. The resulting Pareto exponents ranged from 1.15 in 1900 to 2.03 in 2010 . This anomaly between 1.15 and 2.03 arises because the central limit theorem distorts the Zipf distribution toward normal in both sparsely populated counties that contained many populated places and in large populated places that spanned several counties. When counties were first established, they often contained single population centers. As time passed the differences between populated places and counties has distorted the Zipf distribution. For example, in South Florida the counties Miami-Dade, Broward and West Palm Beach all make up one populated area. Nonetheless, attempts to produce a Zipf distribution by aggregation of counties in places like SE Florida, HoustonGalveston, Greater New Orleans, and Greater New York to improve the Zipf fit proved to be an idle curve-fitting exercise.
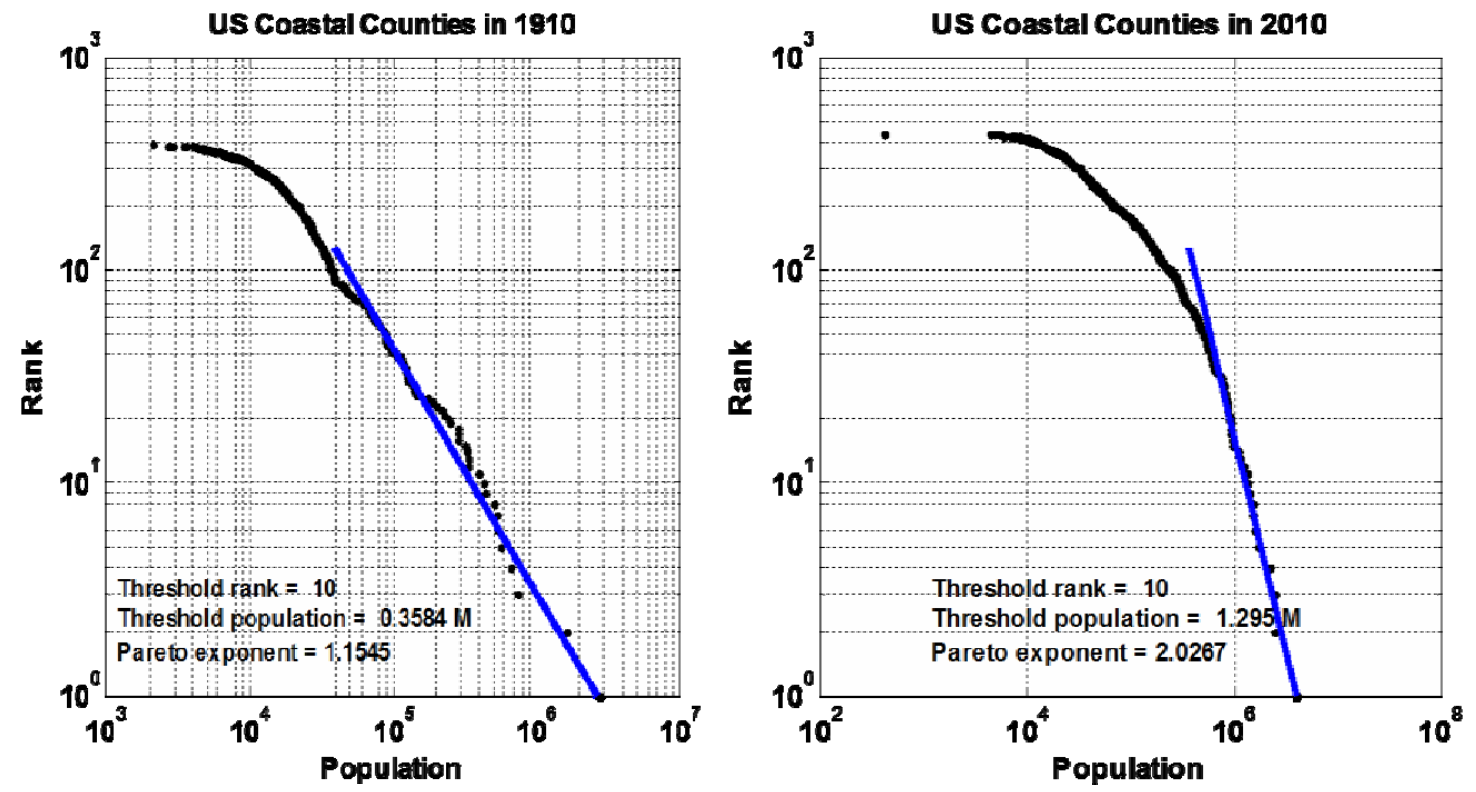

Figure 2. Pareto distributions of Population using census data for $1910(\alpha=1.15)$ and 2010 $(\alpha=2.03)$. The central limit theorem distorts distribution because counties do not follow the definition of populated places in later years. 
Model

An alternative approach to testing if damage from tropical cyclones follows a Pareto distribution because assets follow a Zipf distribution is the creation of a MonteCarlo CAT model. Z-CAT, currently in version 1.4 is just such a model. It is written in MATLAB (Figure 3). The model follows Grossi and Kunreuther's (2005) structure for catastrophe models (Figure 4).

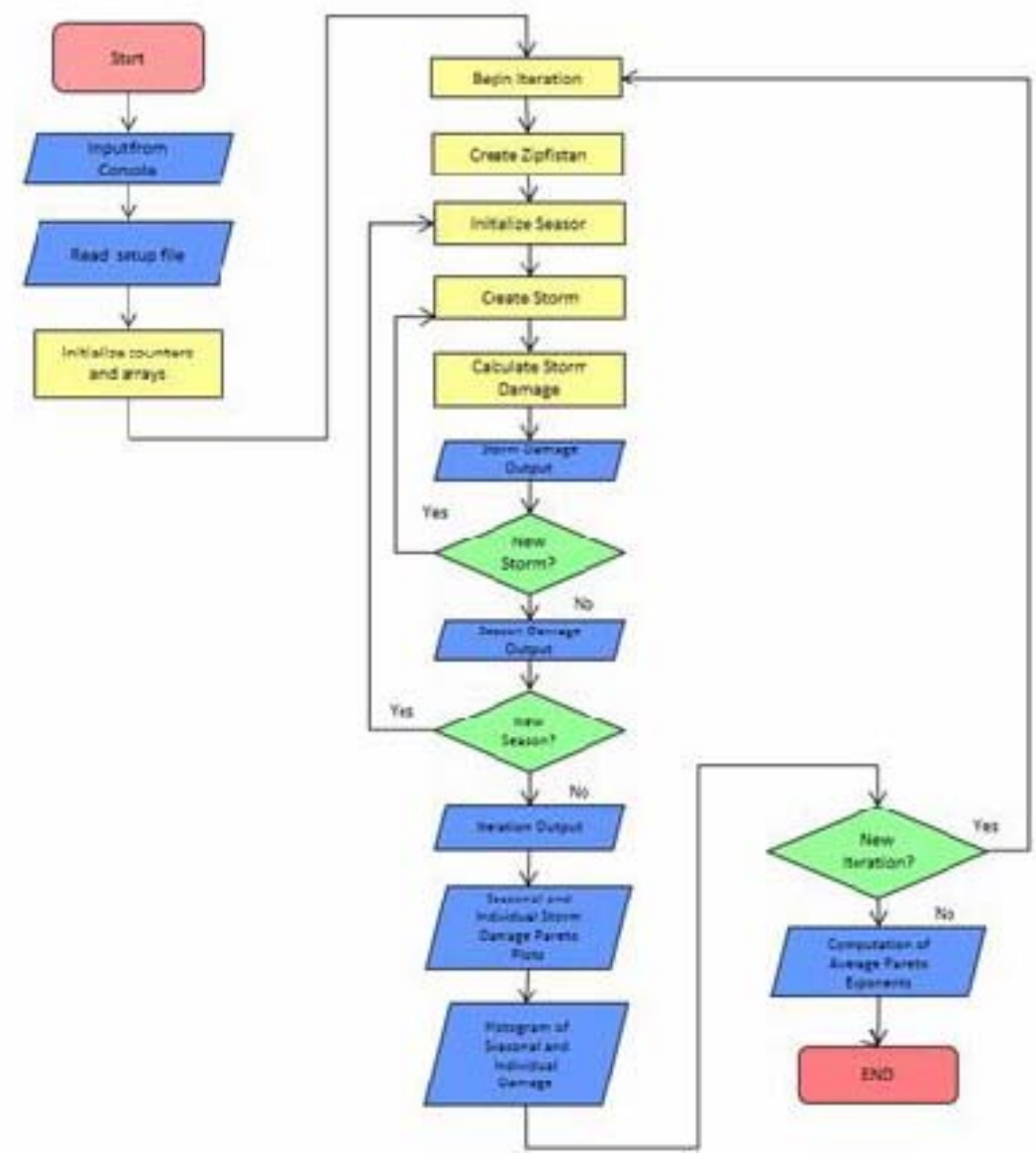

Figure 3. Flowchart of Z-CAT catastrophe model. Z-CAT uses a Monte-Carlo method to simulate century-scale sequences of hurricane seasons, in which landfalls, sizes, wind speeds and other parameters are randomly drawn from specified statistical distributions. 


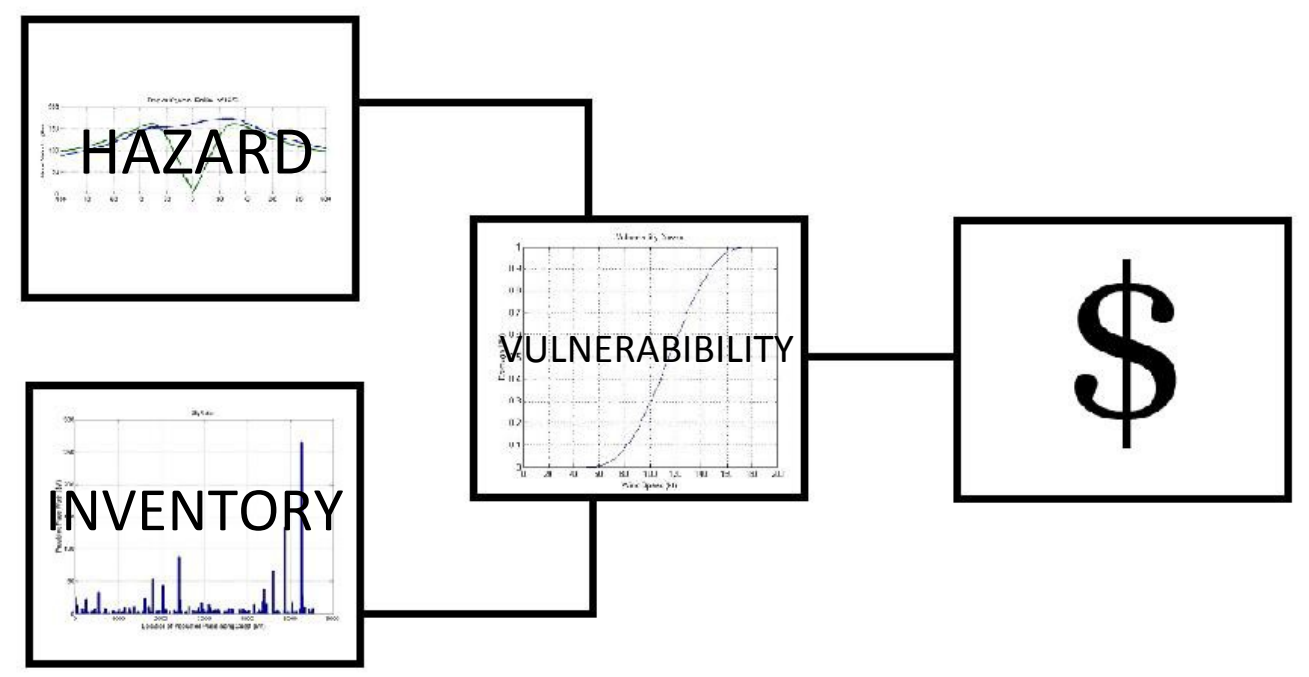

Figure 4. Structure of Catastrophe (CAT) model as envisioned by Grossi and Kunreuther (2005). The left two modules are the hazard which represents the Tropical Cyclones and the inventory which is our virtual country, Zipfistan. To the right, the vulnerability module translates wind to percent damage. That percent damage is calculated by summing the losses to individual populated places into loss in the final module.

Hazard

The hazard module produces the location, frequency and severity of landfalling hurricanes. In Z-CAT the hazard module is based upon a Monte-Carlo method. The number of landfalls obeys a Poisson distribution with a nominal rate of 1.9 landfalling storms per season, although Z-CAT has an option to use a negative binomial distribution. The simulated TCs strike at random points on the coast with spatially constant probability.

The Z-CAT model has a text setup file in which all the parameters are specified and easily changed. In the prototype or base run setup file, Z-CAT simulates 113 seasons. The user specifies wind profile shape: boxcar profile with constant wind throughout the 
storm, or the more realistic Wood-White (2012, figure 5) or Holland (1980) parametric profiles.

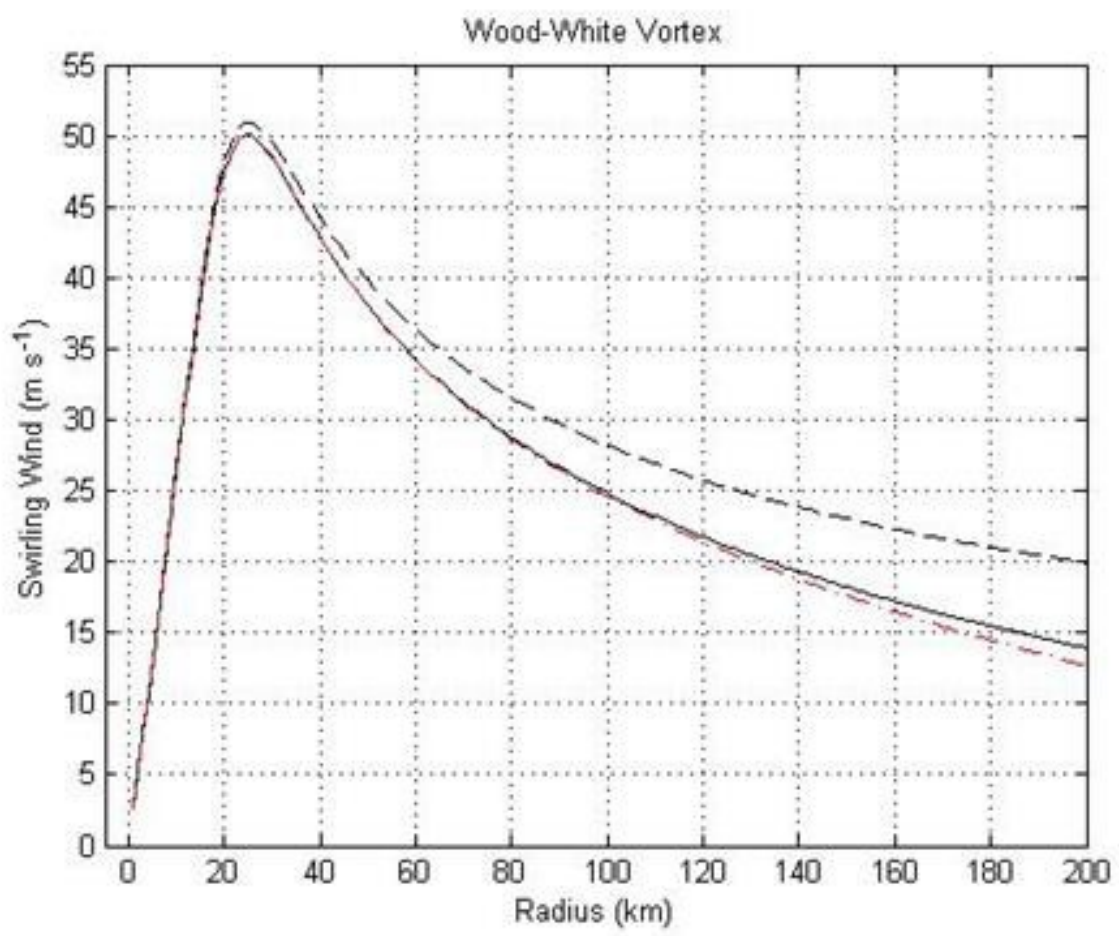

Figure 5. Wood White parameterized hurricane free atmosphere wind profile. The strongest wind (Vmax) occurs at the radius of maximum (Rmax) winds. The slope of the curve from zero to Rmax is defined by Nin while Nout defines the slope from Rmax to the end of the curve. LL or lambda defines the width of the peak of maximum winds.

The setup file has parameters that shape the wind profile curve. The maximum wind determines the peak of the curve while the radius of maximum winds sets the distance of the peak from the center of the storm (Emanuel 2000), these are drawn from uniform and log-normal statistical distributions. The parameter, $\mathrm{N}_{\mathrm{in}}$, defines the shape of the curve from the center to the radius of maximum wind; the base run sets $\mathrm{N}_{\text {in }}$ to $1 . \mathrm{N}_{\text {out }}$ defines the shape of the curve outward from the radius of maximum winds, it is set to .5 
in the base run. Lambda, here LL, defines the width wind maximum and is set to .25 . The setup file specifies the MPI, which sets the range of wind speeds from which the model randomly chooses, the range of sizes, the Poisson rate of landfall per season, a factor that applies a translational speed to the storm, and the reduction in wind due to surface roughness. The base run specifies values of these parameters close to normal values for the present climate. The wind speed ranges from barely a hurricane to a strong category 5. Surface roughness, determines the percentage of the free-atmosphere wind experienced at the surface (Franklin et al. 2003).

Inventory

In commercial CAT models the inventory module is a database of the property values, locations and characteristics. In Z-CAT the inventory consists of 200 population centers. The population centers are ranked following Zipf's law. All 200 populated centers are assigned property values proportional to population. Zipfistan's New York, “Zipfopolis" is valued at $\$ 256$ billion. The populated centers are then randomly scattered linearly along the straight coastline, ready to be hit with the random storms.

Vulnerability

The vulnerability module contains damage functions that link wind speeds to structural damage. The vulnerability curve (figure 6) used here has a sigmoidal shape based on the Saffir Simpson scale (Simpson and Saffir 1974). 


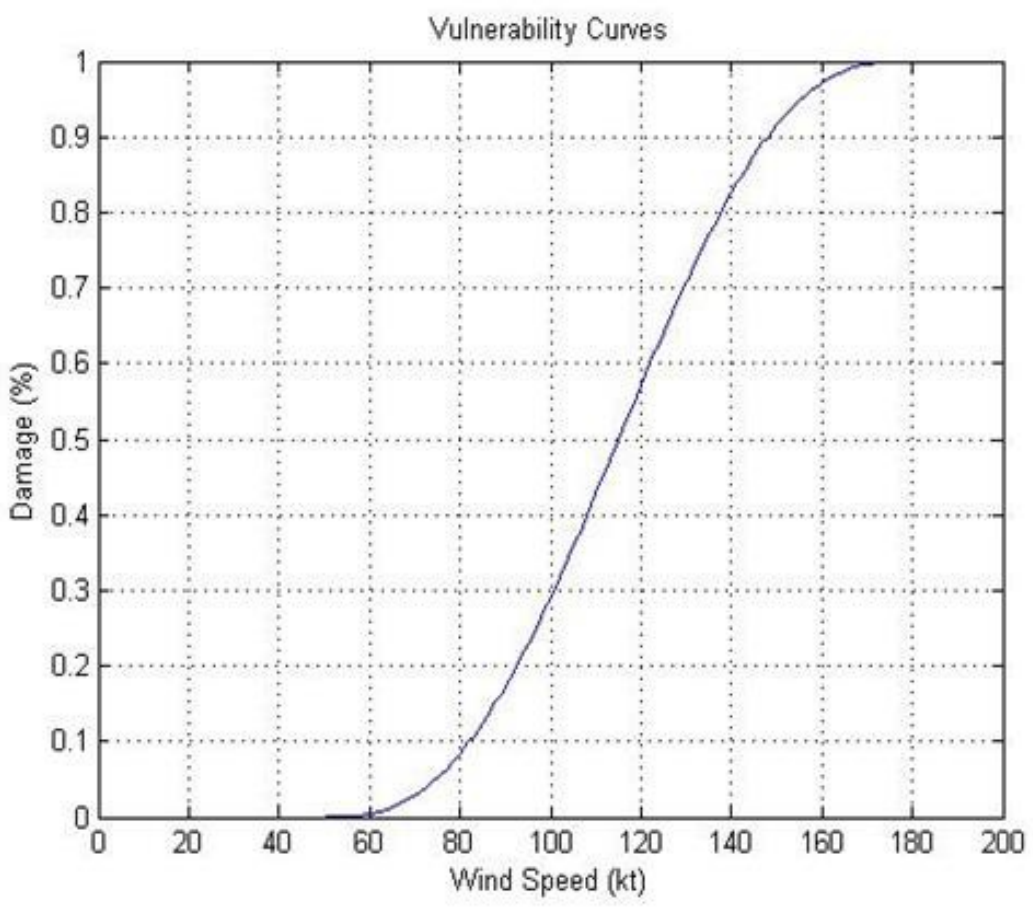

Figure 6. A vulnerability function which defines percent damage due to wind speeds. In this case, damage begins at 45 kts with complete destruction occurring at $165 \mathrm{kts}$.

The Saffir Simpson scale describes the damage to be expected at different wind speeds, stratified into five categories. The Z-CAT vulnerability module converts wind at each populated center to percent damage using a polynomial vulnerability curve determined by the Saffir-Simpson thresholds of initial damage and total destruction. The default values are $34 \mathrm{kt}$ and $180 \mathrm{kt}$. These thresholds are set in Z-CAT's setup file. Varying these thresholds is a way to represent the changing in building standards to make structures more (or less) survivable.

Loss

The loss module translates physical damage to ground-up losses. Z-CAT enters the vulnerability curve with the local wind speed at each populated place to compute the 
percentage damage. During the course of each simulated season, damage from each storm is subtracted from the total value at the location. The remaining value of the location is subject to further damage by subsequent storms. All populated places have their values reset to original values at the start of the next virtual season. At the end of each season, the seasonal and individual storm damage is used to calculate $\alpha$, the Pareto exponent. Damage is ranked from largest to smallest and plotted on log-log axes. Then a linear fit is made to the log of damage as a function of log rank on the tail of the distribution, as defined in the setup file. In Z-CAT's base run, the threshold is set to the most damaging 20 percent seasons and the most damaging of 15 percent storms. If running more than one realization, at the end of all realizations, average Pareto exponents are calculated for both seasonal and individual storm damage. The outputs are therefore, individual storm damages for each season, total damages, and Pareto exponents for both seasonal and individual storms and average total damage.

Tuning

In order to achieve realistic results, some tuning of the parameters was necessary. The parameters have realistic ranges of values. The model was run several times with different combinations of the parameters. Increasing the number of populated places created an increase in the Pareto exponent because of the central limit theorem averaging over larger numbers of places. The MPI wind speeds were selected to range from 65 to 180 knots to coincide with the range thresholds from a category 1 hurricane to a strong category 5 . The vulnerability curve range was selected to begin damage at 45 knots, within the range of tropical storm speeds up to 180 knots. The vulnerability curve range 
determines the start of damage at locations away from the landfall point but that are still experiencing tropical storm winds. The parameter FRIC_FRAC, which determines the amount of surface roughness is observationally $80 \%$ of the wind outside the eye and $90 \%$ under the eyewall for marine exposures (Franklin et al. 2003) but winds even a short distance inland are much less. The coastal value in our prototype model is .7, meaning the hurricane's winds are reduced by 30 percent at the land surface.

The tail of the distribution spans values where the cumulative distribution becomes linear on the log-log graph. The boundary of the tail, $P_{o}$, is also selected setup file; nominally $15 \%$ and $20 \%$, respectively. Values for the prototype setup files, also called the base run, appear in table 1.

\begin{tabular}{|c|c|c|c|c|c|}
\hline \multicolumn{6}{|c|}{ Set up Parameters for Prototype } \\
\hline RUN_ID & WBASE & W_BOTO & 45 & Nin & 1 \\
\hline StartYear & 1899 & W_BOTR & 0 & Nout & -0.5 \\
\hline Coast_Length & 5536 & W_TOP0 & 180 & LL & 0.25 \\
\hline RATE_0 & 1.9 & W_TOPR & 0 & pop_places & 200 \\
\hline RATE_R & 0 & YRO & 1899 & zipf_max & 265 \\
\hline MPI_BOTO & 65 & ORDER & 2 & seasons & 113 \\
\hline MPI_BOTR & 0 & WP & WW & threshold_sea & 0.2 \\
\hline MPI_TOP0 & 180 & B & 1.5 & threshold_stm & 0.15 \\
\hline MPI_TOPR & 0 & IsZipf & 0 & FRIC_FRAC & 0.7 \\
\hline
\end{tabular}

Table 1. The prototype set up produces results with parameters that represent present climate well. All parameters used are listed. 


\section{RESULTS}

Z-CAT Simulating 113 Hurricane Seasons

Z-CAT creates several outputs, including figures to document the coastline and storms. The model first creates a coastline with Zipf-distributed assets (figure 7). The length of the coastline is $5536 \mathrm{~nm}$, the same as that of the United States coastline.
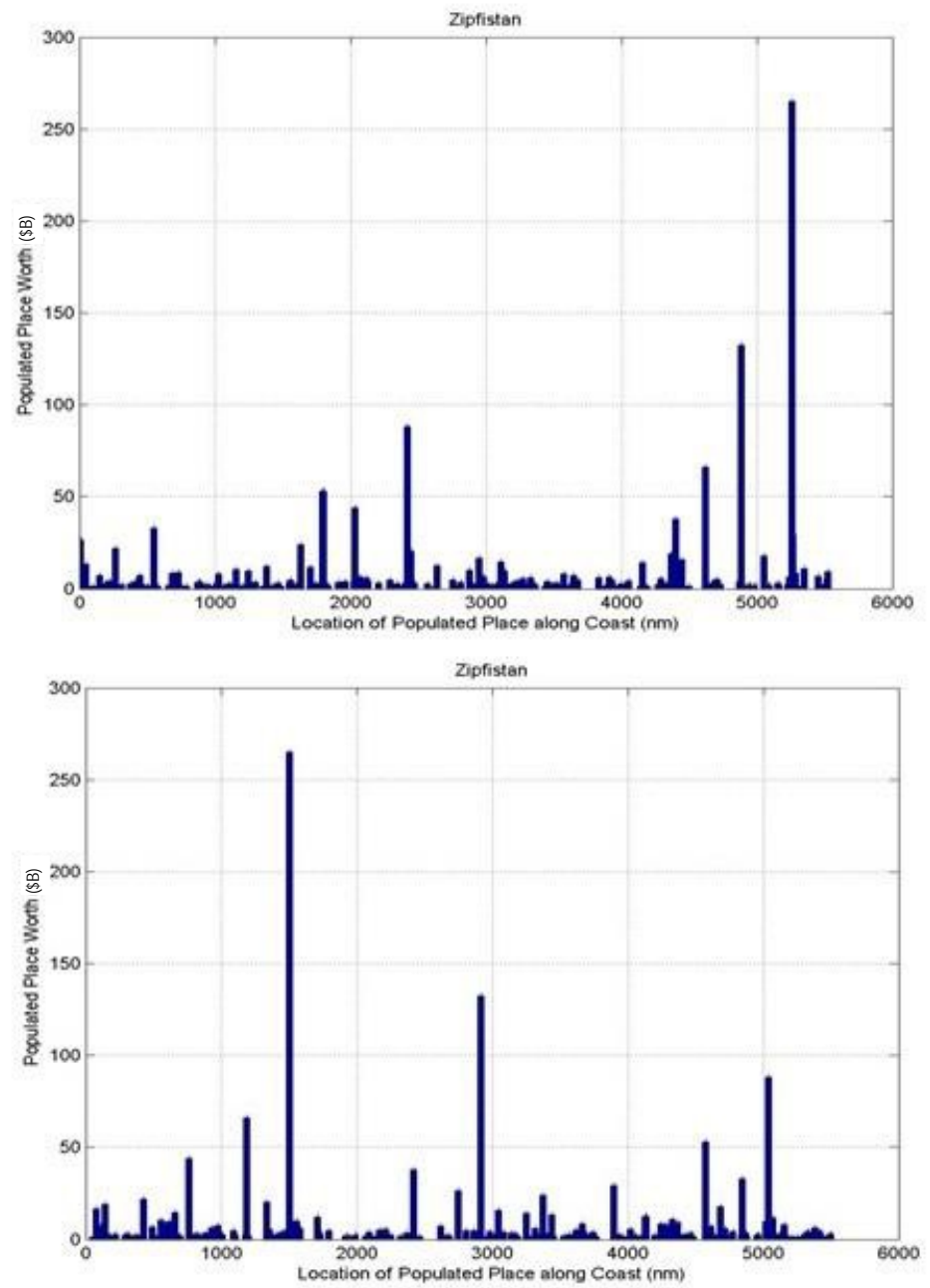

Figure 7. Examples of Z-CAT virtual coastlines. They are assigned property values obeying a Zipf's law and then scattered randomly. The most valuable population center is worth $\$ 256$ billion. 
The user can prompt the model to use the same Zipfistan demographics in each realization or he/she can set up the model to create a new one each time. Figure 7 presents two different Zipfistan coastline simulations that reflect Zipf' law. The power law is clearly illustrated by a few large populated places standing above the clutter of smaller ones.

Within each season the default Z-CAT set up generates landfalls that follow a Poisson distribution with rate 1.9 storms per season. The simulated number of landfalls per season can range from none to seven. They are assigned names to aid in differentiation among cases. Once Z-CAT computes the effect of an individual storm, it graphs the storm wind profile and a bar graph showing the damage to populated places. Figures 8 and 9 show examples.
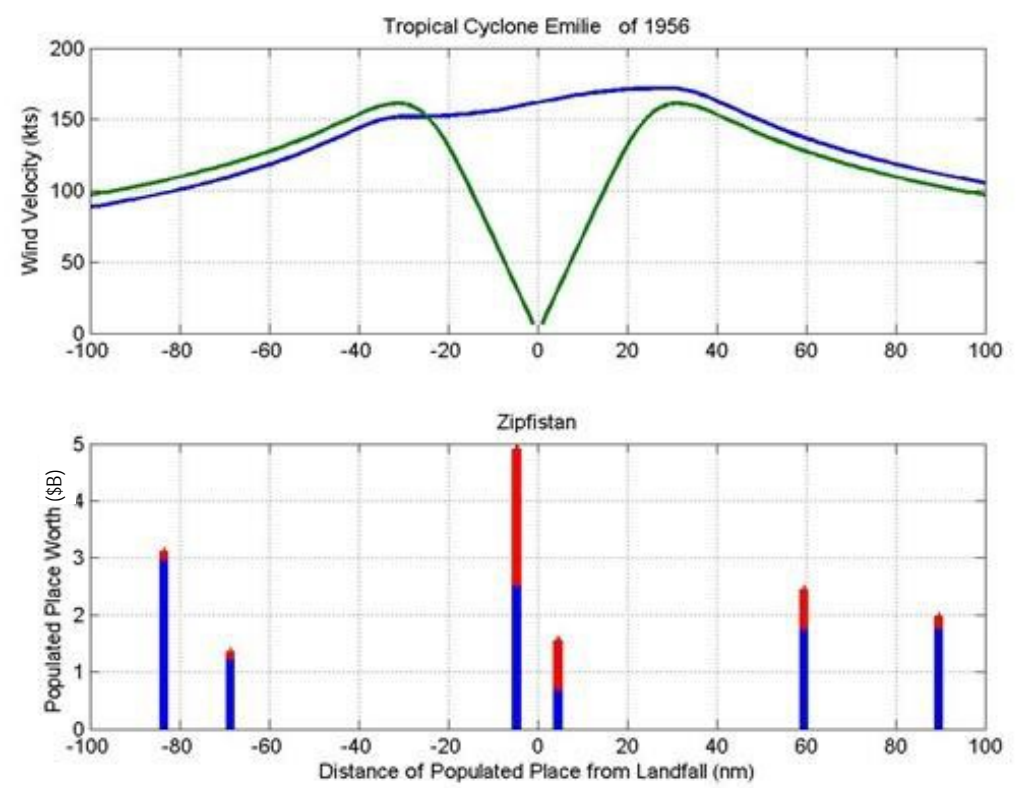

Figure 8. Example of TC generated by Z-CAT. Top panel: Radial wind profile of wind as a function of cross-track distance. Green shows symmetric Wood-White wind profile. Blue includes the effect of cyclone motion and extension of wind across the front of the eye. Bottom panel: Total height of bars indicate pre-storm wealth. The red part of the bars is the damage accrued while blue shows remaining wealth after the storm. 
The green line in the top subplot shows the axially symmetric wind profile. The blue line shows the effective wind taking into account storm translation and passage of the front of the eyewall over places in the path of the eye. On the right side of the storm the translational speed of the storm adds to the symmetric wind causing the winds there to be stronger in the "hazardous semi-circle" than those on the left, in the "navigable semi-circle," where it subtracts. The bottom subplot shows populated places values. The $\mathrm{x}$ axis is distance from the landfall point while the $\mathrm{y}$ axis shows the asset value of each location. The total heights of the bars represent the value of the locations at the beginning of the season. The red part depicts damage that occurred so far during the current season and blue shows the remaining value after the storm. In this case, the storms had
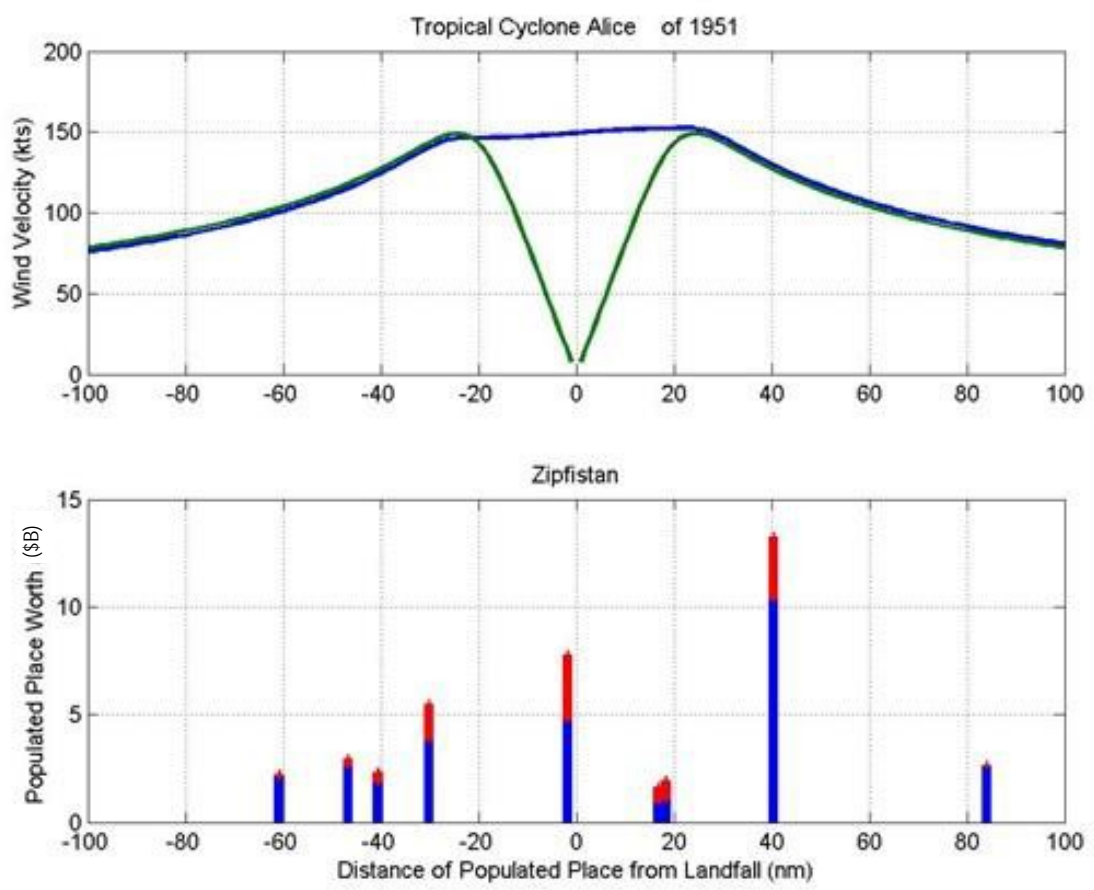

Figure 9. A second example of a TC generated by Z-CAT. As is apparent, Z-CAT is able to produce a range of storms with differing damage potential. 
maximum winds of about $160 \mathrm{kt}$ and $150 \mathrm{kt}$ respectively. The populated places near TC Emilie's landfall point experienced damages of nearly $50 \%$ of their net value. For the most valuable place, that proportion equals to about $\$ 2.5$ billion dollars. A less-valuable place, which is the same distance from the center, had damages of less than one million. Since the larger-valued place has more property to destroy, it experiences greater damage. In the real world, this effect dominates when a storm makes landfall in a large populated place like Miami, FL. On the other hand if it makes landfall in a small town on the coast of Texas not much happens. If a hurricane destroys Miami, a lot more money gets blown away than if it destroys Kennedy County, TX, population 416.

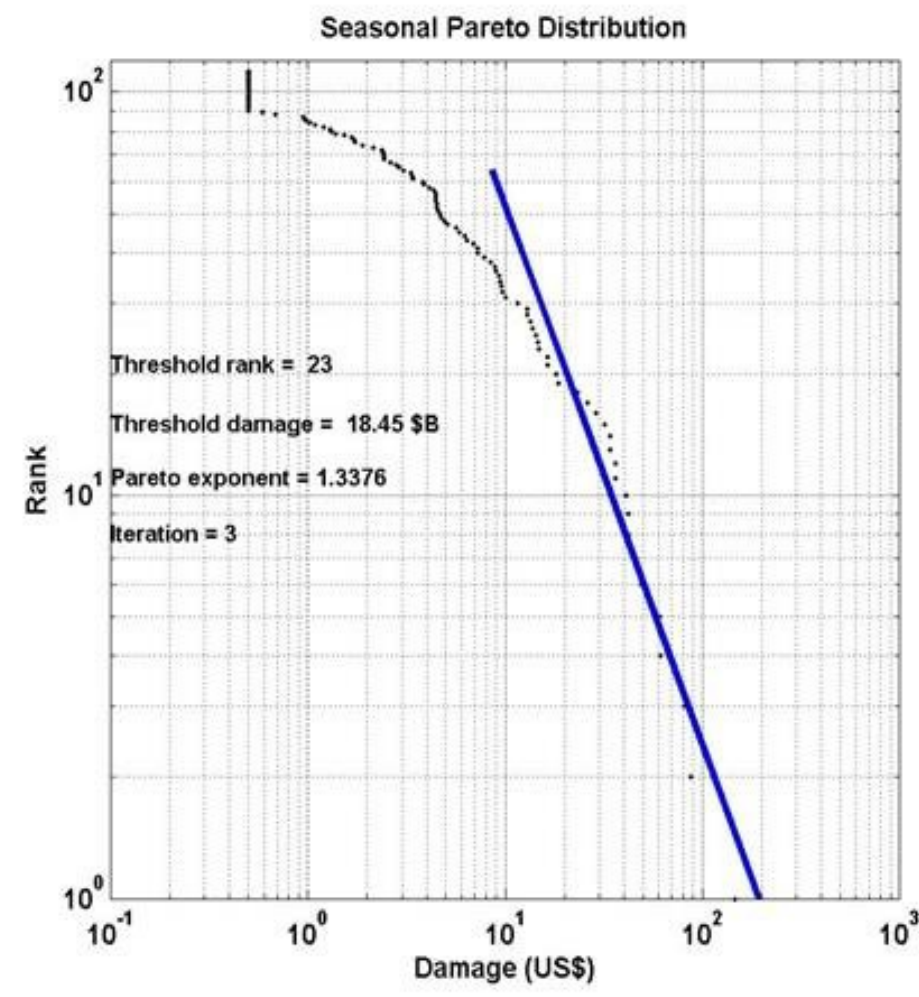

Figure 10. Pareto distribution of seasonal damage produced by Z-CAT. The tail of the distribution fitted to the blue line which has a Pareto Exponent of 1.33, comprises the 23 most damaging seasons. 
At the end of each virtual season Z-CAT generates log-log graphs with ranked damage plotted for both whole seasons and individual storms. The Pareto power law is fitted to the tail of the distribution and the exponent, alpha $(\alpha)$, is calculated. Alpha is the link for connecting damage to assets at risk. Figure 10 shows the graph for seasonally aggregated damage for the 113 simulated seasons in one realization. The first ranked season that has the most damage is located on the bottom right of the graph. The line represents the slope of the distribution's tail. It should be close to one because of the Zipf distribution of assets. The example shown in Figure 9 represents only one realization; number 3 of 20. The threshold rank determines how many seasons (or storms) are included in the calculation of the Pareto exponent. In the example above, the most

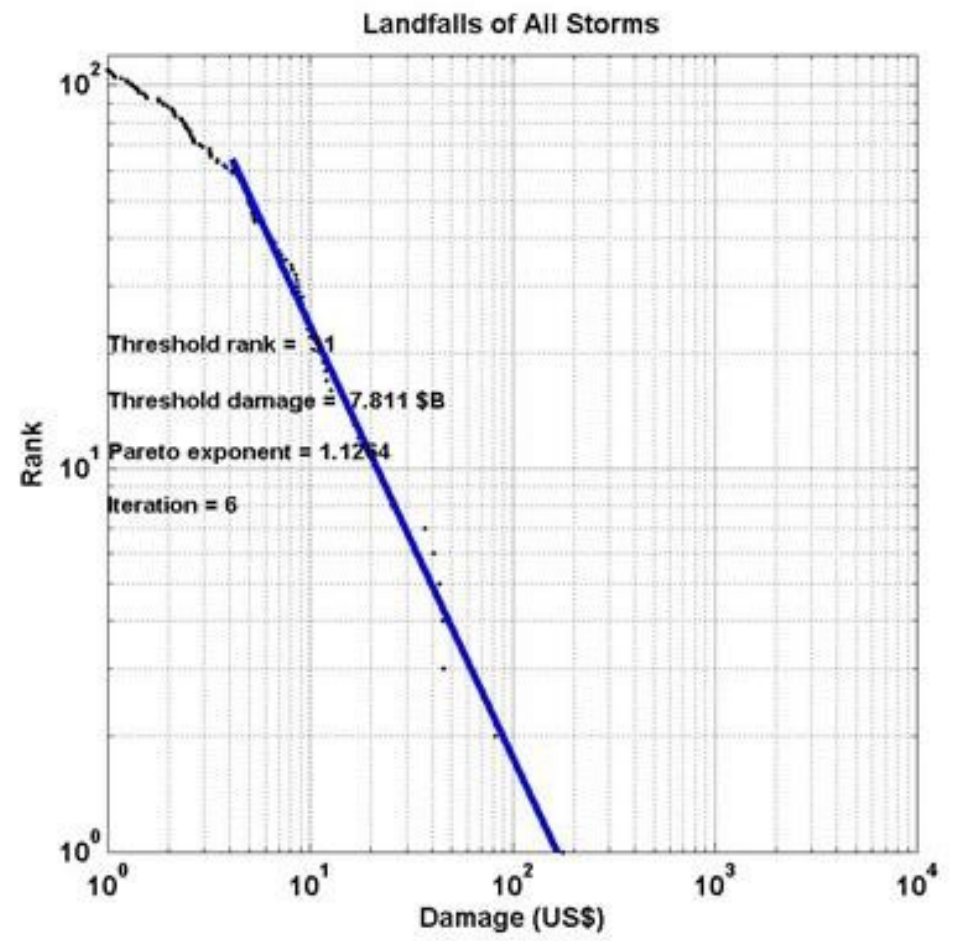

Figure 11. Pareto distribution of damage of all TCs produced by Z-CAT. This is the same as the previous Pareto distribution except the damage is not aggregated into seasons. In this case, the Pareto alpha exponent is 1.12 for the 31 most damaging storms. 
damaging 23 seasons represent the top $20 \%$. The threshold damage is that from the $23^{\text {rd }}$ ranked season; $\$ 18.45$ billion dollars. The Pareto exponent $(\alpha)$ calculated for this realization is 1.34. This number comes close the 1.37 Pareto exponent calculated from actual normalized damage data. (Pielke 2008, Willoughby 2012)

Figure 11 is the same kind of log-log plot of rank as a function of damage, but for individual storms. In this case, the threshold rank is the 31st most damaging storm; the top $15 \%$. The threshold damage is about $\$ 7$ billion. This figure shows the $6^{\text {th }}$ iteration of 20 and $\alpha=1.12$. The result of this realization is also close to reality which was calculated to be 1.14 based upon 1900-2012 normalized data. The Pareto exponents are extremely variable across realizations. To see how different realizations compare, twenty different iterations were run using the same random number generator. Thus, each realization had a different coastline and experienced different storms. The average and median Pareto exponents for both seasonally aggregated damage and individual storms were calculated as well as for the annual total damage for both situations.

Table 2 shows the results from these runs. From the table, one can see that the Pareto exponents vary widely from .90 to 1.7 for individual storms and from .96 to 2.0 for seasons. The total damage per realization of 113 seasons varies from $\$ 1083$ billion dollars to $\$ 1536$ billion. The average damage per storm varies from $\$ 4.7$ billion to $\$ 6.8$ billion and for seasons it varies from $\$ 9.6$ to $\$ 13.2$ billion dollars. The median Pareto exponent for individual storms over the 20 realizations is 1.28 while the median seasonal Pareto exponent is 1.34 . 


\begin{tabular}{|c|c|c|c|c|c|c|c|}
\hline \multicolumn{8}{|c|}{ Tropical Cyclone Data for 20 Simulations of Z-CAT } \\
\hline Iteration & $\begin{array}{l}\text { Alpha } \\
\text { Storms }\end{array}$ & $\begin{array}{c}\text { Alpha } \\
\text { Seasons }\end{array}$ & $\begin{array}{c}\text { Total } \\
\text { Damage (B) }\end{array}$ & $\begin{array}{c}\text { Average } \\
\text { Damage per } \\
\text { Storm (B) } \\
\end{array}$ & $\begin{array}{c}\text { Average } \\
\text { Damage per } \\
\text { Season (B) } \\
\end{array}$ & $\begin{array}{c}\text { Damage } \\
\text { Threshold } \\
\text { Storms (B) } \\
\end{array}$ & $\begin{array}{c}\text { Damage Thres } \\
\text { hold for Seas } \\
\text { ons (B) }\end{array}$ \\
\hline 1 & 1.22 & 1.29 & $\$ 1,184.22$ & $\$ 5.81$ & $\$ 10.48$ & $\$ 9.71$ & $\$ 15.82$ \\
\hline 2 & 1.26 & 1.19 & $\$ 1,491.09$ & $\$ 6.75$ & $\$ 13.20$ & $\$ 12.41$ & $\$ 17.75$ \\
\hline 3 & 1.27 & 1.34 & $\$ 1,334.41$ & $\$ 6.61$ & $\$ 11.81$ & $\$ 12.13$ & $\$ 18.45$ \\
\hline 4 & 1.39 & 1.64 & $\$ 1,536.29$ & $\$ 5.98$ & $\$ 13.60$ & $\$ 10.64$ & $\$ 22.46$ \\
\hline 5 & 1.11 & 1.13 & $\$ 1,489.04$ & $\$ 6.80$ & $\$ 13.18$ & $\$ 9.76$ & $\$ 15.87$ \\
\hline 6 & 1.13 & 1.07 & $\$ 1,083.32$ & $\$ 5.21$ & $\$ 9.59$ & $\$ 7.81$ & $\$ 11.61$ \\
\hline 7 & 1.73 & 1.61 & $\$ 1,161.55$ & $\$ 6.02$ & $\$ 10.28$ & $\$ 13.89$ & $\$ 18.23$ \\
\hline 8 & 1.57 & 1.53 & $\$ 1,217.78$ & $\$ 5.41$ & $\$ 10.78$ & $\$ 11.23$ & $\$ 17.52$ \\
\hline 9 & 1.67 & 1.60 & $\$ 1,320.33$ & $\$ 6.35$ & $\$ 11.68$ & $\$ 14.32$ & $\$ 20.38$ \\
\hline 10 & 1.29 & 1.28 & $\$ 1,260.00$ & $\$ 6.12$ & $\$ 11.15$ & $\$ 11.23$ & $\$ 17.21$ \\
\hline 11 & 1.08 & 1.28 & $\$ 1,347.55$ & $\$ 6.74$ & $\$ 11.93$ & $\$ 9.86$ & $\$ 17.30$ \\
\hline 12 & 1.59 & 2.01 & $\$ 1,417.54$ & $\$ 6.27$ & $\$ 12.54$ & $\$ 14.23$ & $\$ 26.16$ \\
\hline 13 & 1.26 & 1.40 & $\$ 1,354.08$ & $\$ 6.13$ & $\$ 11.98$ & $\$ 11.31$ & $\$ 19.06$ \\
\hline 14 & 1.31 & 1.45 & $\$ 1,240.04$ & $\$ 5.59$ & $\$ 10.97$ & $\$ 9.89$ & $\$ 16.26$ \\
\hline 15 & 1.10 & 1.32 & $\$ 1,104.31$ & $\$ 4.97$ & $\$ 9.77$ & $\$ 7.94$ & $\$ 14.93$ \\
\hline 16 & 1.45 & 1.47 & $\$ 1,099.32$ & $\$ 4.78$ & $\$ 9.73$ & $\$ 9.84$ & $\$ 14.82$ \\
\hline 17 & 0.93 & 0.97 & $\$ 1,179.82$ & $\$ 6.41$ & $\$ 10.44$ & $\$ 7.89$ & $\$ 11.41$ \\
\hline 18 & 1.41 & 1.52 & $\$ 1,236.01$ & $\$ 5.89$ & $\$ 10.94$ & $\$ 11.77$ & $\$ 19.91$ \\
\hline 19 & 1.11 & 1.14 & $\$ 1,307.60$ & $\$ 6.14$ & $\$ 11.57$ & $\$ 9.48$ & $\$ 15.60$ \\
\hline 20 & 1.30 & 1.35 & $\$ 1,218.61$ & $\$ 5.75$ & $\$ 10.78$ & $\$ 10.11$ & $\$ 16.32$ \\
\hline Average & 1.308435 & 1.379630 & $\$ 1,279.14$ & $\$ 5.99$ & $\$ 11.32$ & $\$ 10.77$ & $\$ 17.35$ \\
\hline Median & 1.28 & 1.34 & $\$ 1,250.02$ & $\$ 6.07$ & $\$ 11.06$ & $\$ 10.37$ & $\$ 17.25$ \\
\hline
\end{tabular}

Table 2. Results from 20 simulations of Z-CAT. The columns are iteration run, Pareto exponent for individual storms, Pareto exponent for aggregated seasons damage, Total damage, average damage per season and per storm, and the damage threshold for both seasons and individual storms. 
Damage Comparison

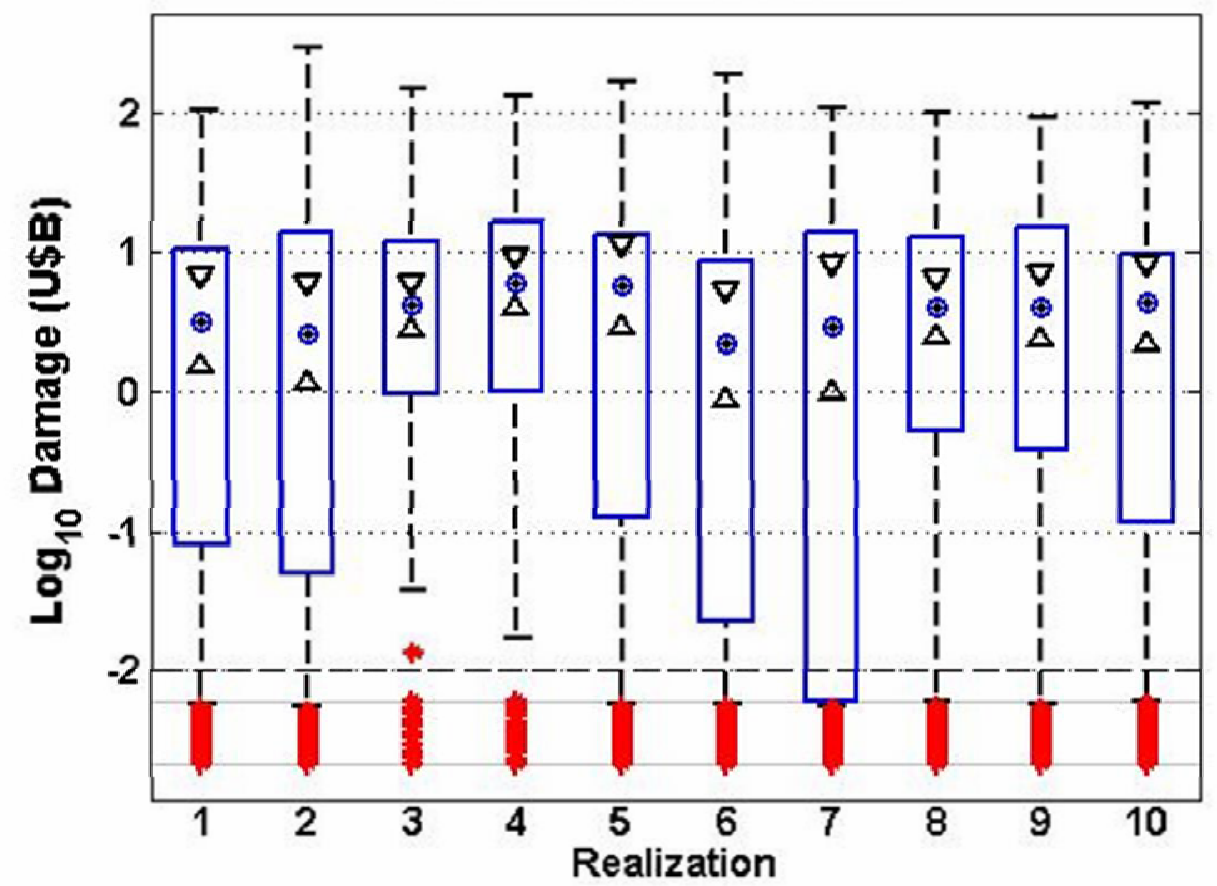

Figure 12. Boxplots of damage comparisons on a log scale for ten realizations of Z-CAT. There is a large variance among realizations as well as many zero damage outliers. These occur because of Z-CAT's lack of bypassing and tropical storms.

Boxplots illustrate the differences in damage from ten 113 season realizations (Figure 12). All of the realizations produced many seasons with zero damage. This result arises because Z-CAT accumulates damage only from landfalling hurricanes. TCs that bypass the coastline, without technically making landfall, but still cause wind damage, are not modeled. Z-CAT also does simulate tropical storms with winds of 34 - 63 knots. The boxplot also demonstrates the wide range in values of damage. It is important to realize that we only have one realization of reality and the variance among realizations is large. 
Z-CAT Simulating Changes in Climate and Building Standards

The ability to adjust Z-CAT's input parameters aids study of sensitivities. Some factors of concern are increases of MPI over time as the globe warms (Murnane and Elsner 2012), or increases (or decreases) in number of storms per season (Bender et al. 2010, Knutson et al. 2010, Emanuel 2013). Another factor to consider is changes in building codes which could be made to guard against increase of these hazards by raising the vulnerability curve.

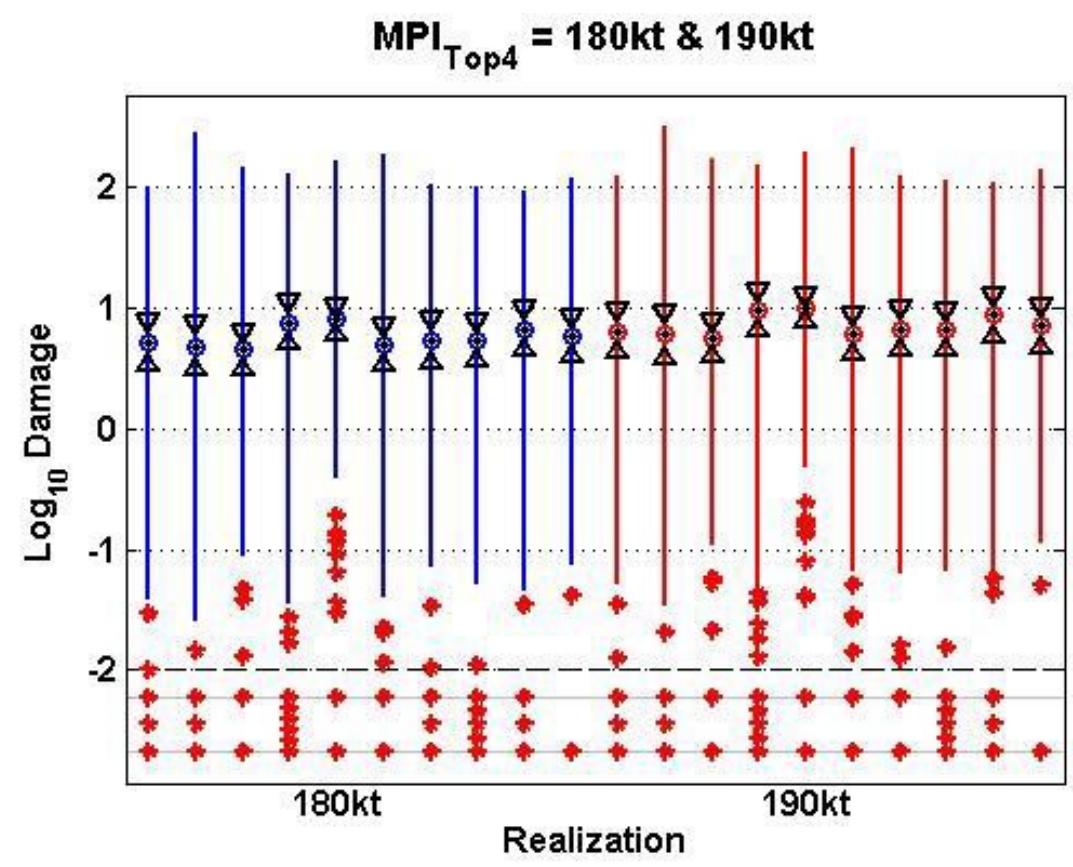

Figure 13. Boxplots showing 10 realizations of MPI at 180kts (blue) and 10 with MPI at 190kt (red) of logarithmic damage. No statistical significant damage difference is seen with this 10kt change.

First, increases of MPI were tested using different values for the top threshold of wind speed with 10 realizations for each. The range of thresholds for the top MPI was from $170 \mathrm{kts}$ to $210 \mathrm{kts}$ in ten knot increments, with the base run MPI $=180 \mathrm{kts}$. The logarithmic box plot shown in figure 13 depicts the differences in damage as the top 
threshold of the MPI is changed from $180 \mathrm{kt}$ to $190 \mathrm{kt}$, and to $210 \mathrm{kt}$. The triangles show the range of statistically significant differences. The farther apart the triangles are, the more the values must differ for significance. Consistent with the Z-CAT base run realizations, these boxplots also show many zero values because of the lack of bypassing and tropical storms. When MPI increases by $10 \mathrm{kt}$, approximately $1 / 2$ Saffir- Simpson category, the change in damage is substantial, but not statistically significant. But statistical significance is achieved when the MPI is increased from $180 \mathrm{kt}$ to $210 \mathrm{kt}$, equivalent to $1 \frac{1}{2}$ categories, and the damage almost doubles.

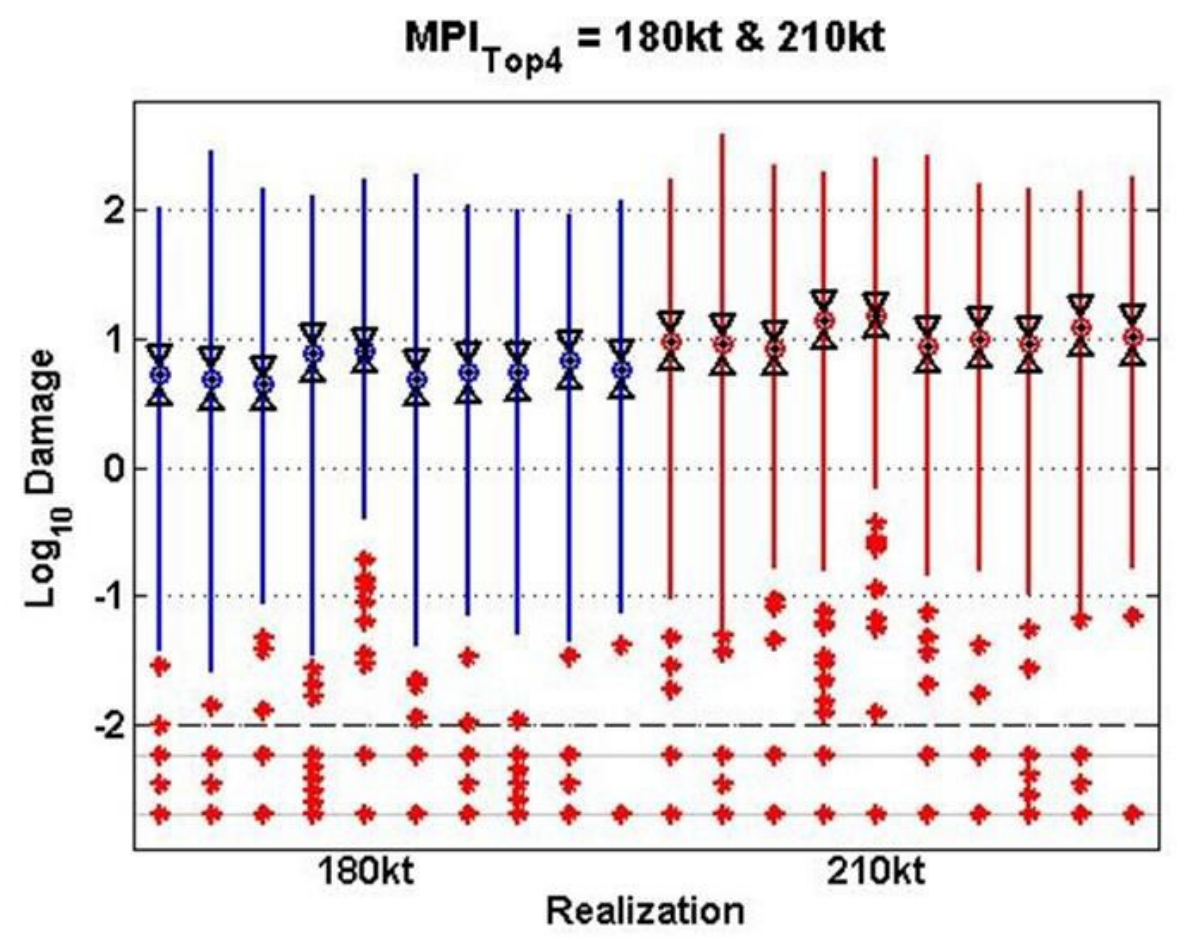

Figure 14. Boxplots showing 10 realizations of MPI at 180kts (blue) and 10 with MPI at 210kt (red) of logarithmic damage. The differences look small because of the logarithmic scale but the difference shows significant differences. 
Statistical significance is very much at issue here, as three standard nonparametric test, Mann Whitney, Kolmogorov-Smirnov, and Bootstrap illustrate. Figure 15,16 and 17 show the fraction of 100 realization in which the tests yielded statistical significance on the left side and the values of the median and mean damage generated by changing the parameters. Ensembles of simulations (Fig 15) that compare MPIs of $170 \mathrm{kt}, 190 \mathrm{kt}$, 200kt, and $210 \mathrm{kt}$ with the baseline $180 \mathrm{kt}$ value show increasing power ( the probability that the test will reject the null hypothesis of no effect when an effect exists) that approaches the generally accepted $70-80 \%$ only when the damage more than doubles.
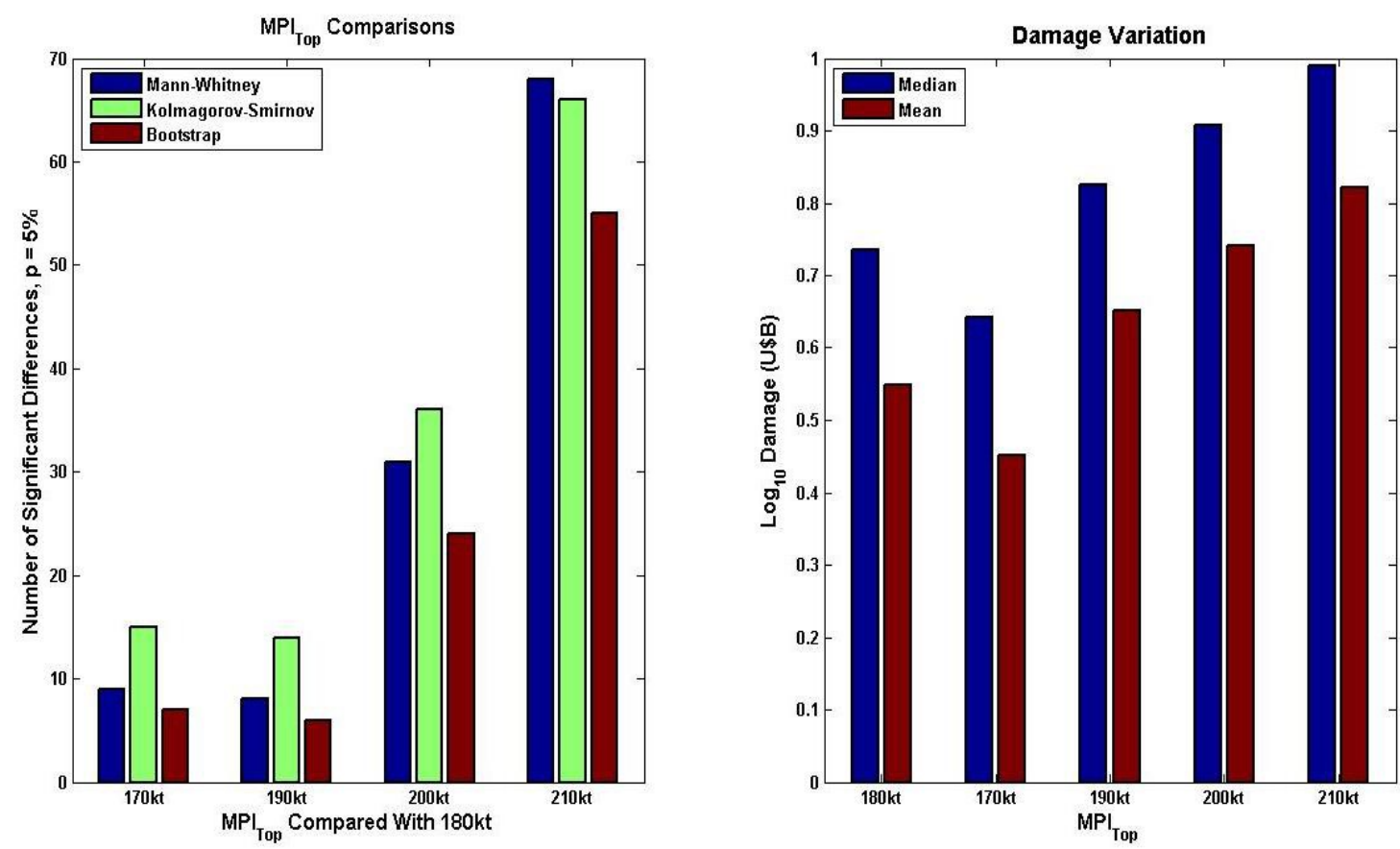

Figure 15. Bar graphs on the left show Mann Whitney, Kolmogorov- Smirnov and Bootstrap statistical tests for changing values of Z-CAT parameters of MPI. The right side shows the damage variation for the different scenarios. Here MPI changes from $170 \mathrm{kt}$ to $210 \mathrm{kt}$ with statistical power only when the MPI is $210 \mathrm{k}$. 
Similarly, figure 16 shows the difference in damage for ten realizations of Z-CAT with the landfall rate at 1.9 and then at 4.0. The boxplots show the significant statistical difference with the large change in landfall rate which causes the doubling in damage. Statistical tests with the rate of landfalls per season (Figure 17) showed that the rate had to increase from the baseline value (1.9) to 3.5 to attain powers of $70-80 \%$.

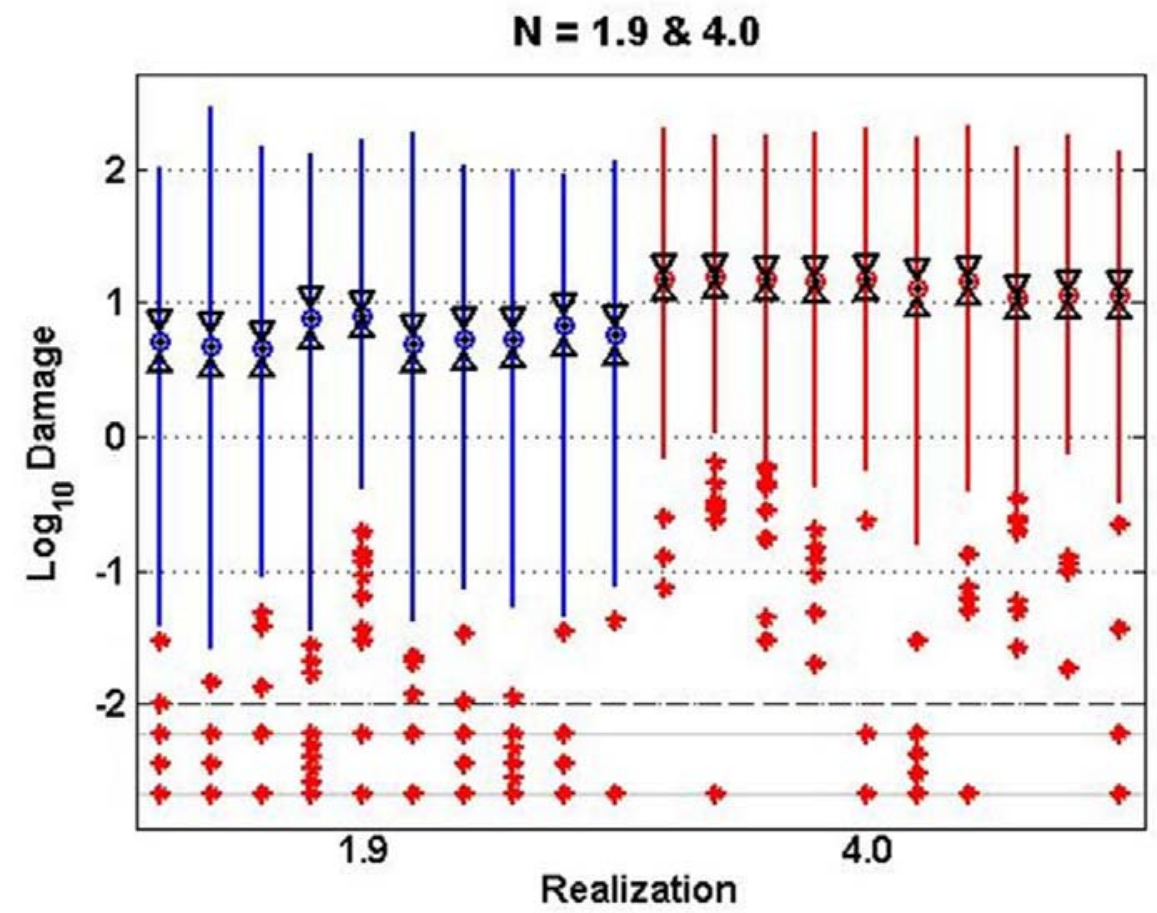

Figure 16. Boxplots showing ten realizations of Z-CAT's landfall rate set at 1.9 and ten other realizations with the landfall rate increased to 4.0. 

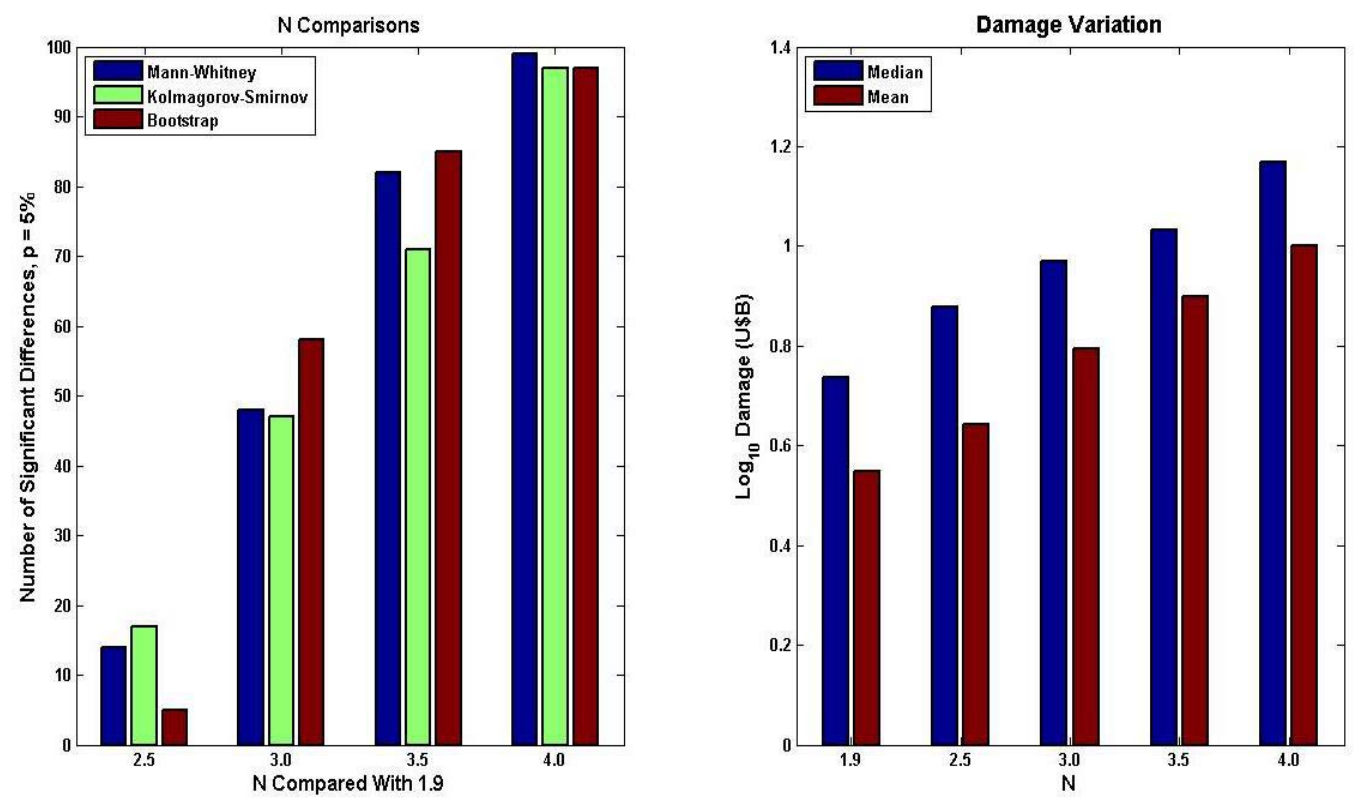

Figure 17. Bar graphs showing statistical tests for changing values of Z-CAT parameters of landfall rates. The left shows the different statistical tests and the right side shows the damage variations for changes in landfall rates from 1.9 to 4.0.

Finally, the vulnerability curve was tested. Changing the top and bottom thresholds affects the shape of the entire sigmoid curve. The bottom threshold, where damage begins to occur was lowered from $45 \mathrm{kt}$ to $25 \mathrm{kt}$ in $5 \mathrm{kt}$ increments while the top threshold was changed from 180 to 210 . Figure 18 shows the damage difference over 10 realizations with the top of the threshold at $180 \mathrm{kt}$ and $210 \mathrm{kt}$ where it is evident that the large change in the curve adversely affects the damage. Again, the three statistical tests, Mann Whitney, Kolmogorov-Smirnov, and bootstrap were done for both the comparisons of the bottom and top thresholds (Figure 19, 20). The tests reveal that large increases in damage were required for $>70 \%$ power. A salient result is that substantial increases in damage were needed to produce statistical significance using Mann-Whitney, Kolmogorov-Smirnov, and Bootstrap statistical tests. 


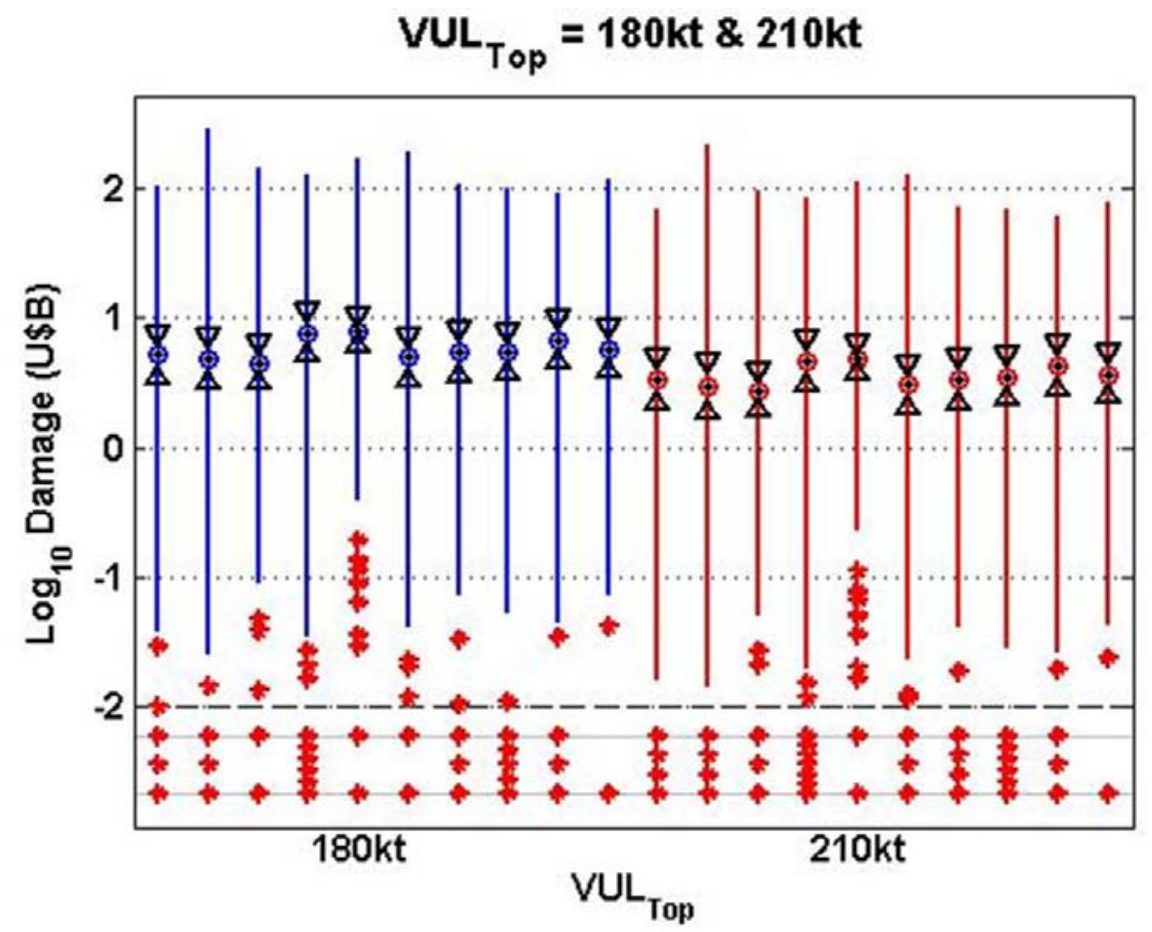

Figure 18. Boxplots showing ten realizations of Z-CAT's vulnerability threshold set at $180 \mathrm{kt}$ (blue) and ten other realizations set at 210kt (red).
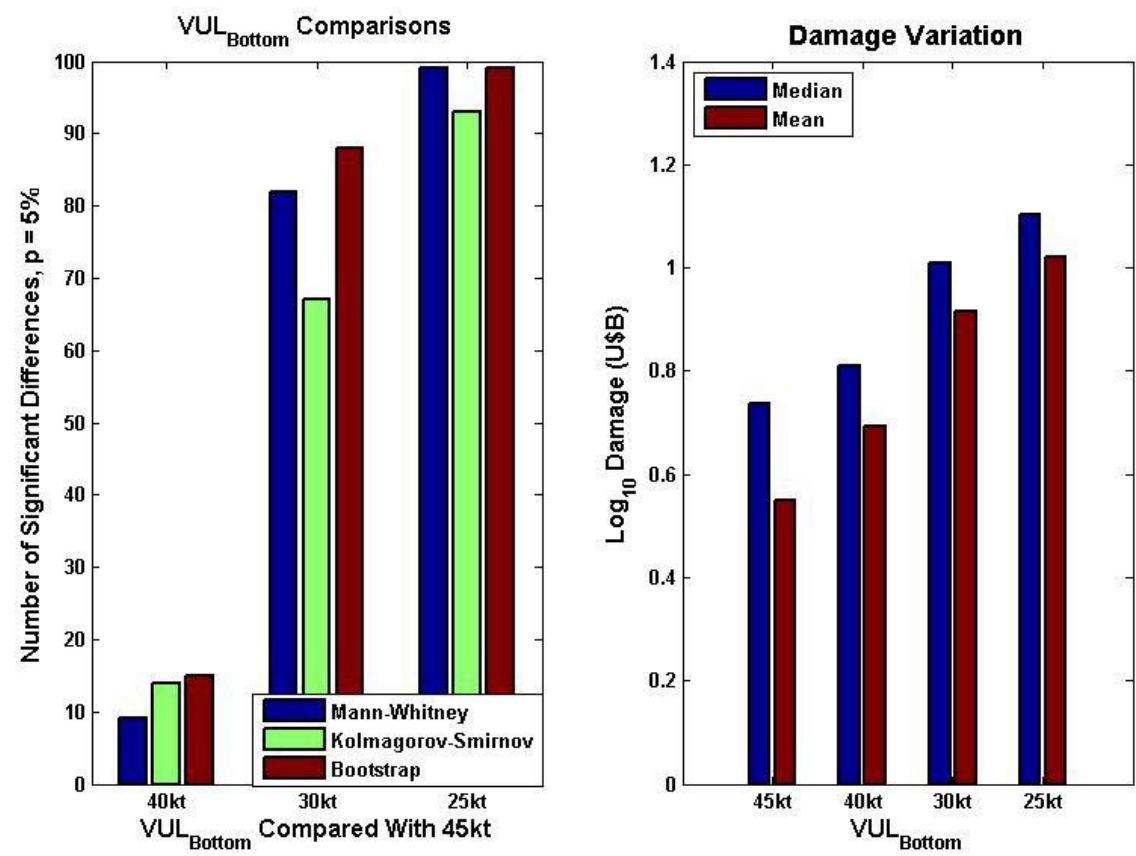

Figure 19. Bar graphs on the left show Mann Whitney, Kolmogorov- Smirnov and Bootstrap statistical tests for the bottom of the vulnerability curve. The right shows damage variation. Changes in the vulnerability curve show significant differences are small with a $5 \mathrm{kt}$ difference, there is a large jump at 25-30kt. 

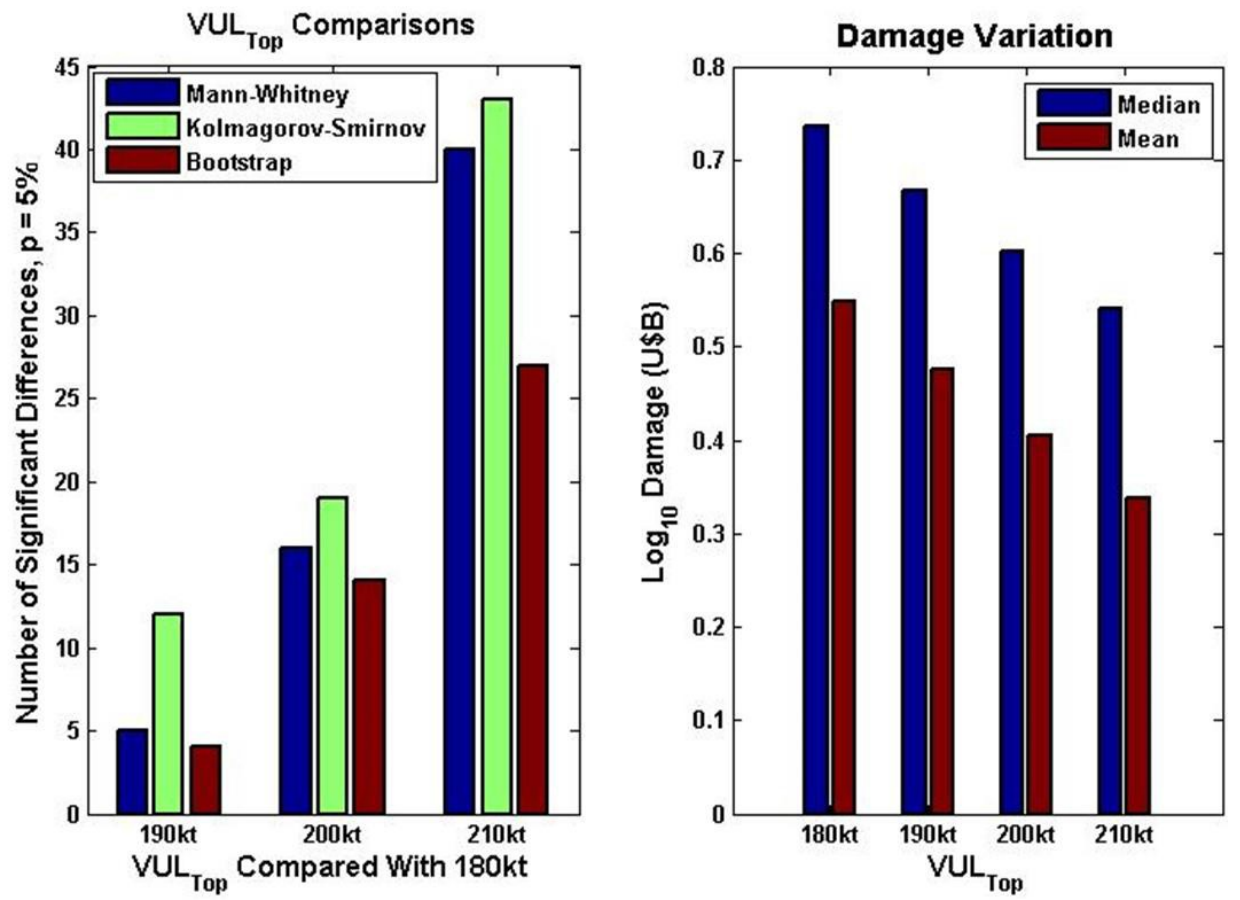

Figure 20. Bar graphs on the left show Mann Whitney, Kolmogorov- Smirnov and Bootstrap statistical tests for changing values of the top of the vulnerability curve and the right shows damage variation for changes from 180kt-210kt. Changes in the vulnerability curve show significant differences when the top changes from $180 \mathrm{kt}$ to $210 \mathrm{kt}$. 


\section{DISCUSSION}

While Z-CAT has been tuned to produce realistic results, opportunities exist to improve its realism. Most significantly, the model climatology and demographics are geographically and temporally constant. In reality, MPI and landfall probabilities would become smaller northward because of the cooler ocean temperatures. Z-CAT has the same MPI thresholds and landfall probability throughout. Incorporating geographic variations to landfall frequency would also help make Z-CAT more realistic.

Another potential improvement is addition of storm surge to the damage calculation. Presently Z-CAT's damage is produced solely by wind, but storm surge and flooding cause a big percentage of US Hurricane damage. The wind however is still a factor to reassess in that the populated places in Zipfistan are distributed linearly along the coast. Adding populated places inland and simulating inland wind decay would yield to more realistic results.

Some climate factors that are not programmed into the catastrophe model include El Nino Southern Oscillation (ENSO, e.g., Pielke and Landsea 1999) and the Atlantic Multidecadal Oscillation (AMO, e.g., Goldenberg et al. 2001). Both of these climate signals have been studied in conjunction with the intensity and frequency of tropical cyclones in the Atlantic basin. "El Nino" is an episodic ocean increase in temperatures over the equatorial Pacific Ocean that occurs at 3-5 year intervals. El Nino events produce increased vertical shear which in turn causes a decrease of Atlantic TC formation. The AMO has a multidecadal time scale as opposed to ENSO which has a 3-5 year recurrence interval. The AMO is a 60-70 year cyclic increase and decrease in 
Atlantic Ocean temperatures. It has been shown to affect the climate in North America. The warm AMO phase causes a decrease in shear leading to an increasing in Atlantic TC genesis. The cool phase brings increasing shear coupled with more frequent El Niño events. Neither of these factors are included in the model, but they may contribute to increased variability and also provide an opportunity to assess Z-CAT realism.

Tuning the parameters to result in more realistic values may also affect the realism of the model. While all the parameters are within justifiable ranges, it is difficult to say how realistic the model's outputs are since the values differ by a lot and we only have one realization of reality. It would be instructive to evaluate the actual number of populated centers in the United States to use in the Zipfistan model. 


\section{CONCLUSIONS}

Normalized historical hurricane damage shows no trends from 1900- 2005 (Pielke

et al. 2008). There is, however, high interannual variability of damage because of random variations in assets near landfall points. Since size and intensity of hurricanes are physically limited, this variability must stem from the distribution of assets at peril. Observationally, most destructive tail of historical hurricane damage hurricanes follows a Pareto distribution because the assets at hazard follow Zipf's law.

Z-CAT, an idealized catastrophe model, was created to test this hypothesis. In Z-CAT, the hazard module produces randomly generated hurricanes with stochastic wind fields. The inventory module is a Zipf distribution of clusters of value randomly scattered along a straight coastline. A vulnerability function is a sigmoidal curve that joins the thresholds of initial damage and total destruction. In the nominal runs losses presented here are calculated at the end of each simulated season and accumulated for 113 seasons.

In a representative run, Z-CAT finds a median seasonal Pareto exponent equals 1.34 and an all storms Pareto median exponent of 1.28. This lends strong support to the hypothesis that the Pareto distribution of impacts stems from a Zipf distribution of assets, even though the model has some unrealistic features.

Z-CAT is easily set up to simulate different scenarios that arise from variation in MPI, landfall rate, or vulnerability curve thresholds. A key preliminary result is that damage needs to approximately double before statistical significance emerges with conventional nonparametric tests. 


\section{REFERENCES}

Bender, M.A., T.R. Knutson, R.E. Tuleya, J.J. Sirutis, G.A.Vecchi, S.T. Garner, and I. Held, 2010: Modeled Impact of Anthropogenic Warming on the Frequency of Intense Atlantic Hurricanes. Science. 22. 237, DOI: 10.1126/science.1180568, 454-458.

Blake, E. S., T. B. Kimberlain, R. J. Berg, J. P. Cangialosi, and J. L. Beven III,2013 : Tropical Cyclone Report: Hurricane Sandy (AL182012). Tech. Rep. AL182012, NOAA/National Hurricane Center, 157 pp. [Available online at http://www.nhc.noaa.gov/data/tcr/AL182012_Sandy.pdf.]

Emanuel, K.A., 2013: Downscaling CMIP5 climate models shows increased tropical cyclone activity over the 21 st century. Proc. Nat. Acad. Sci., 110, doi/10.1073/pnas.1301293110

Emanuel, K., S. Solomon, S., D. Folini, S. Davis, and C. Cagnazzo, 2013: Influence of tropical tropopause layer cooling on Atlantic hurricane activity. J. Clim., 26, 2288-2301.

Emanuel, K. A., R. Sundararajan, and J. Williams, 2008: Hurricanes and global warming: Results of downscaling the IPCC AR4 simulations. Bull. Amer. Met. Soc., 89, 347-367, DOI:10-1175/BAMS-89-3-347.

Emanuel, K. A., 2000: A statistical analysis of tropical cyclone intensity. Mon. Wea. Rev., 128, 1139-1152.

Emanuel, K. A., 1999: Thermodynamic control of hurricane intensity. Nature, 401, 665669.

Emanuel, Kerry A., 1986: An Air - Sea Interaction Theory for Tropical Cyclones. Part I: Steady-State Maintenance. Journal of the Atmospheric Sciences. 43 No.6, 585-604.

Frank, W. M., and E. A. Ritchie, 1999: Effects of environmental flow upon tropical cyclone structure, Mon. Wea. Rev., 127, 2044-2061.

Franklin, J.L, M.L. Black, K. Valde, 2003: GPS Dropwindsonde Wind Profiles in Hurricanes and Their Operational Implications. Weather and Forecasting, 18, 32-44.

Gabaix, Xavier.,1999: Zipf's law for cities: An Explanation. The American Economic Review, 89, 129-132.

Goldenberg, S.B., C.W. Landsea, A.M. Mestas- Nuñez, W.M. Gray, 2001: The Recent Increase in Atlantic Hurricane Activity: Causes and Implications. Science, 293, pp. 474479 DOI: $10.1126 /$ science. 1060040

Grossi, Patricia, Kunreuther, H.,2005: Catastrophe Modeling: A New Approach to Managing Risk. Springer Science and Media Inc, New York. Print. 245 pp. 
Holland, Greg. 1980: An Analytic Model of the Wind and Pressure Profiles in Hurricanes. Monthly Weather Review, 108, 1212-1218

Katz, Richard W., 2002: Stochastic Modeling of Hurricane Damage. Journal of Applied Meteorology, 41, 754-762

Knabb, R.D., J.R. Rhome, D.P. Brown, 2005: Tropical Cyclone Report: Hurricane Katrina (AL122005). Tech. Rep. AL122005,.NOAA/National Hurricane Center, 43 pp. [Available online at http://www.nhc.noaa.gov/pdf/TCR-AL122005_Katrina.pdf]

Knutson, T.R., J.L. McBride, J. Chan, K. Emanuel, G. Holland, C. Landsea, I. Held, J.P. Kossin, A.K. Srivasta, and M.Sugi, 2010: Tropical Cyclones and Climate Change" Nature Geoscience, Review Article, 21 February 2010, DOI: 10.1038/NGEO779, 7 pp.

Landsea, C. W., C. Anderson, N. Charles, G. Clark, J. Dunion, J. Fernandez-Partagás, P. Hungerford, C. Neumann, and M. Zimmer, 2004: The atlantic hurricane database reanalysis project. Documentation for 1851-2010 alterations and additions to the HURDAT Database. In Hurricanes and Typhoons, R. J. Murnane and K-B. Liu, eds, 177 -221, New York, Columbia Univ. Press.

Marks, F. D., Jr., R.A. Houze, Jr., and J. F. Gamache, 1992: Dual-aircraft investigation of the inner core of Hurricane Norbert. Part I: Kinematic structure. J. Atmos. Sci., 49, 919942.

Mainelli, M., M. De Maria, L. K. Shay, and G. Goni, 2008: Application of oceanic heat content estimation to operational forecasting of recent Atlantic category 5 hurricanes.Wea. Forecasting, 23, 3-16.

Murnane, R.J., and Elsner, J.B., 2012: Maximum windspeed and US hurricane losses. Geophys.Res.Lett., 39, L16707, doi: 10.1029/2012GL052740.

Pielke Jr., R.A.,Jr., Gratz,J. Landsea, C.W., Collins, D., Saunders, M.A., and Musulin, R., 2008: Normalized Hurricane Damage in the United States: 1900-2005. Natural Hazards Review, 9(1), 29-42.

Pielke, R. A., Jr., and Landsea, C. W. , 1999. "La Niña, El Niño, and Atlantic hurricane damages in the United States.” Bull. Am. Meteorol.Soc., 80(10), 2027-2033.

Shapiro, Lloyd J., Willoughby, H., 1982: The response of Balanced Hurricanes to Local Sources of Heat and Momentum. Journal of the Atmospheric Sciences, 39, 378- 394.

Simpson, R. H., and H. Saffir, 1974: The hurricane disaster-potential scale, Weatherwise, 27(4), $169 \& 186$.

Sitkowski, M., J. P. Kossin, and C. M. Rozoff, 2011: Intensity and structure changes during hurricane eyewall replacement cycles. Mon. Wea. Rev., 139, 3829-3847.

Taleb, N. N., 2007: The Black Swan: The Impact of the Highly Improbable, Random House, New York, 366 pp. 
Vickery, Peter J. Lin, J. Skerlj,P. Twisdale, L., Huang, K., 2006: HAZUZ-MH Hurricane Model Methodology. I: Hurricane Hazard, Terrain, and Wind Load Modeling. Natural Hazards Review, 7, 82-93.

Vickery, Peter J. Lin, J. Skerlj,P. Twisdale, L., Huang, K., 2006: HAZUZ-MH Hurricane Model Methodology. II: Damage and Loss Estimation. Natural Hazards Review, 7, 94103.

Watson, Charles C., Johnson, Mark E., 2004: Hurricane Loss Estimation Models. Bulletin of the American Meteorological Society, 85, 1713- 1726.

Willoughby, H. E, 2012a: Distributions and Trends of Death and Destruction from Hurricanes in the United States, 1900-2008 Natural Hazards Review. 13(1), 57-64.

Willoughby, H.E, 2012b: Is a Trillion Dollar Hurricane Season Possible? $30^{\text {th }}$ conference on Hurricanes and Tropical Meteorology, 7D5, American Meteorological Society.

Willoughby, H. E., 1990: Temporal changes of the primary circulation in tropical cyclones. J. Atmos. Sci., 47, 242-264.

Wood, V. T., L.W. White, H.E. Willoughby, and D.P. Jorgensen, 2013: A New Tropical Cyclone Parametric Profile Model. Monthly Weather Review., 141(6), 1884-1909. 